\title{
WestVirginiaUniversity
}

THE RESEARCH REPOSITORY @ WVU

Graduate Theses, Dissertations, and Problem Reports

2005

\section{The role of reinforcement rate on fluency}

Vennessa L. Walker

West Virginia University

Follow this and additional works at: https://researchrepository.wvu.edu/etd

\section{Recommended Citation}

Walker, Vennessa L., "The role of reinforcement rate on fluency" (2005). Graduate Theses, Dissertations, and Problem Reports. 2296.

https://researchrepository.wvu.edu/etd/2296

This Thesis is protected by copyright and/or related rights. It has been brought to you by the The Research Repository @ WVU with permission from the rights-holder(s). You are free to use this Thesis in any way that is permitted by the copyright and related rights legislation that applies to your use. For other uses you must obtain permission from the rights-holder(s) directly, unless additional rights are indicated by a Creative Commons license in the record and/ or on the work itself. This Thesis has been accepted for inclusion in WVU Graduate Theses, Dissertations, and Problem Reports collection by an authorized administrator of The Research Repository @ WVU. For more information, please contact researchrepository@mail.wvu.edu. 
The role of reinforcement rate on fluency

Vennessa L. Walker

Thesis submitted to the Eberly College of Arts and Sciences

at West Virginia University

in partial fulfillment of the requirements

for the degree of

Master of Science

in

Psychology

Philip N. Chase, Ph. D., Chair

B. Kent Parker, Ph. D.

Jennifer A. Margrett, Ph. D.

Department of Psychology

Morgantown, West Virginia

2005

Keywords: Fluency, Reinforcement Rate, Behavioral Momentum 


\begin{abstract}
The role of reinforcement rate on fluency
\end{abstract}

Vennessa L. Walker

Building skills to high rates and accuracy has been purported to result in fluency, a set of behavioral outcomes identified as retention, endurance, application, problem solving, and stability (REAPS). These outcomes require that the skills persist under changing environmental conditions, and may be conceptualized as examples of resistance to change. As such reinforcement rate should be the critical factor. To test this conceptualization twelve subjects were trained on 5 algebra skills to specified rate and accuracy criteria. Feedback consisting of points, knowledge of results, and corrective feedback was delivered either every 1 or 5 minutes. Stability, application, and problem-solving were assessed after each skill, and retention was assessed 2 weeks after completing all training. No differences were found in accuracy or rate on any of the tests. Present methods are compared to those of previous research in mathematics training, as well as the precision teaching and behavioral momentum literatures. 


\section{Acknowledgments}

I would like to thank the members of my committee for their time and insightful contributions: Jen Margrett, Kent Parker, and Phil Chase. Many thanks also to Nikki Williams and Sarah Sigler, my research assistants, who spent many hours testing and collecting data. I especially would like to thank Phil Chase, my advisor and mentor, for his stalwart patience in this long process and for helping me to develop my research and writing skills.

This thesis may have been the end of me if not for the support of my labmates and the unconditional love from my friends. I'd especially like to thank my ladies for always being there to be a sounding board when I had to vent about "another one bites the dust" and other various trials related to this process. Finally, I would like to thank God for His peace; Philippians 4:6 was an oft-read passage that kept me calm and looking forward.

This research was supported by a generous contribution from the WVU Department of Psychology Alumni Fund. 
Table of Contents

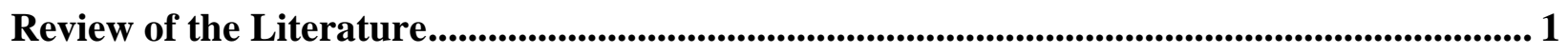

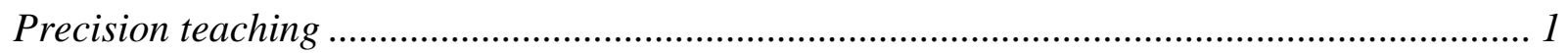

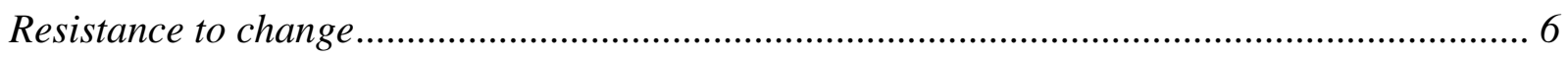

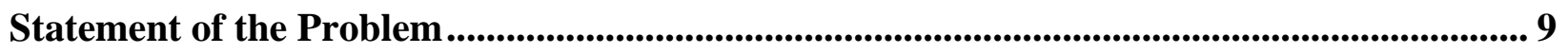

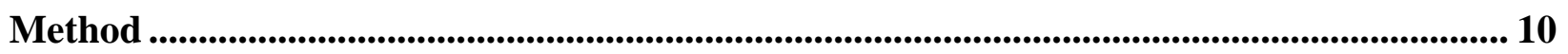

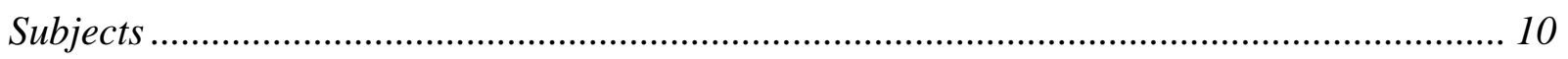

Setting, Apparatus, and Materials ................................................................................. 10

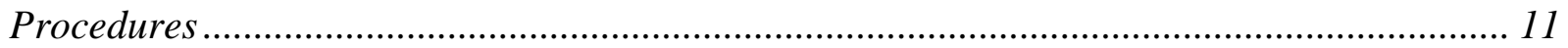

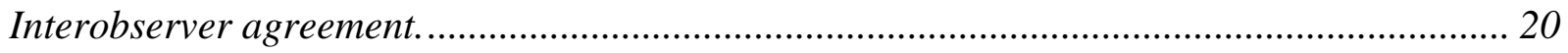

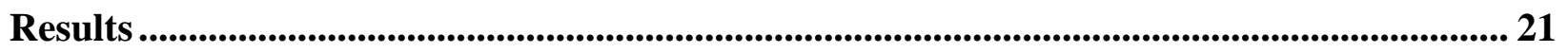

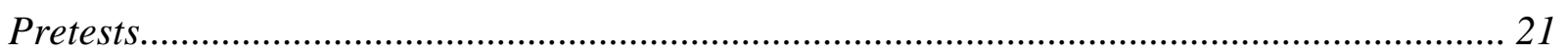

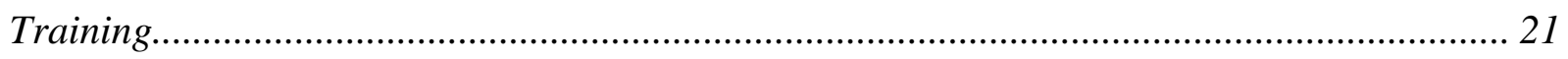

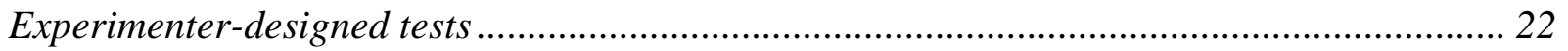

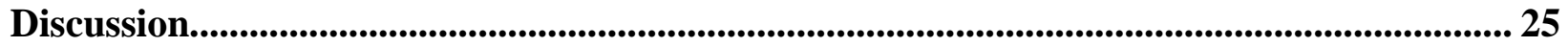

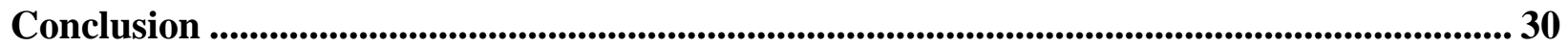

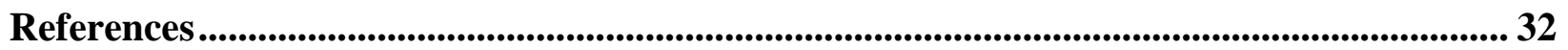


The role of reinforcement rate on fluency

Deficiencies in the educational system are well-documented, particularly regarding early mathematics skills (e.g., Wirt \& Livingston, 2002). Improvements in training are imperative, and recent research has focused on various methods of training students in mathematics (e.g., Kim, 2003; Mayfield \& Chase, 2002; Neef, Nelles, Iwata, \& Page, 2003). One method that has been utilized in training is the precision teaching model (e.g., Chiesa \& Robertson, 2000). This model of teaching involves individualized instruction to train behaviors to high rates and accuracy. According to precision teachers, these methods will lead to fluency, a set of behavioral outcomes with important educational value. The research on precision teaching, while compelling in its demonstration of superior effects compared to regular classroom instruction, is controversial in terms of an explanation for the outcomes it reportedly produces (Binder, 2004; Doughty, Chase, \& O’Shields, 2004). This thesis attempts to synthesize a behavioral explanation of fluency in terms of resistance to change, a phenomenon which has been shown to be strongly affected by reinforcement rate. Based on this conceptualization, the current study attempts to analyze the critical variables involved in fluency, beginning specifically with reinforcement rate.

Review of the Literature

\section{Precision teaching}

Overview. Precision teaching is an individualized method of instruction that uses frequent timed probes and charting of a student's performance to demonstrate learning trends (Binder, Haughton, \& Van Eyk, 1990; Howell \& Lorson-Howell, 1990). Precision teaching also involves component analyses of a target task to determine the smaller tasks that comprise it (Chiesa \& Robertson, 2000). For instance, the task of solving the problem $2+6-4=$ ? is a target task within a basic arithmetic curriculum and is comprised of the component skills of number 
recognition, addition, and subtraction. The goal of precision teaching is to train these component behaviors to occur both accurately and at high rates.

In a precision teaching model (e.g., Chiesa \& Robertson, 2000), students are taught a component skill and then are given practice worksheets. The practice worksheets are then scored immediately by a teacher or even a peer, so students receive feedback on their performance almost immediately after completing an exercise. After receiving feedback on their practice worksheet, students complete a timed probe and chart their performance. Again, the students receive feedback almost immediately regarding their performance on the timed probes, and by charting their performance, they also can see their learning trends over time. Thus, the immediacy of feedback in a precision teaching model is much greater than that of a normal classroom and allows for prompt pinpointing of deficit component skills that must be trained further in order for the composite skill to be learned.

REAPS. According to precision teachers, training component skills to high rates will result in fluency, a set of behavioral outcomes often identified as retention, endurance, application, and performance standards, or REAPS (Binder, 1996). Retention refers to the maintenance of a behavior after some time has elapsed between training and testing. For example, teaching a skill and then testing the students after a week of not practicing would assess their retention of the behavior taught.

Endurance refers to engaging in the behavior for an extended period of time. Precision teachers often will train skills to a particular rate using 1-min timings, but then will assess endurance by testing whether students perform the task accurately and consistently for a longer period of time, such as in a 4-min timing. Endurance also includes stability, which refers to a behavior persisting under distraction conditions. Stability might be assessed in an on-going 
classroom where students are tested with noise and other distractions. If the behavior of interest persists with little disruption, then it is called stable. Because this use of the term stability may be confused with its use in research to describe a criterion for changing experimental conditions, stability will be referred to in this thesis as minimal disruption

Application of a behavior involves engaging in a trained behavior in the presence of new stimuli, but these new stimuli are not discriminative stimuli for the emission of the behavior. In other words, these new stimuli may vary considerably without affecting the discriminative stimuli responsible for occasioning a response. Application has commonly involved responding to word problems or other real world situations, whereby the discriminative stimuli may include operation signs or operational words. In these cases, other stimuli not critical to the emission of the response may include the number of operations required or the specific objects or situations included as details of the question. For instance, in training students to calculate the area of a square, a teacher may demonstrate the equation Area $=$ Length $x$ Width by using a rectangle drawn on the chalkboard. The rectangle is a two-dimensional stimulus and has a certain measurement for both the length and width. Once trained in such a setting, the students presumably may apply the equation to calculate the area of a room. The room is a threedimensional stimulus with different measurements from the two-dimensional squares on which the student received training. The new stimulus of being in a room with walls is different from the training stimulus, because the rectangle now has walls and furniture superimposed on it. These features are not discriminative stimuli for engaging in the behavior of calculating the area, however. Rather, the four right angles and the length and width of the floor are the discriminative stimuli for calculating the area. Another example of application is training students to multiply variables with exponents using only one variable per problem, such as $2 \mathrm{~h}^{2} \cdot 2 \mathrm{~h}^{3}=4 \mathrm{~h}^{5}$, then 
presenting them with application problems that involve multiple variables within a problem as in $2 h^{2} j^{3} \cdot 2 h^{3} j^{2}=4 h^{5} j^{5}$ (Mayfield \& Chase, 2002). In this case, the number of variables included may vary between the training and testing items, but the discriminative stimuli are those stimuli that are critical to the emission of the response required to answer the question.

Problem solving involves combining component skills in novel ways. Although the term “problem solving” has been used colloquially to refer to many different situations, a behavior analytic definition typically refers to Skinner’s (1969) definition of problem solving (e.g., Chase, 2003; Shahan \& Chase, 2002). According to such definitions, a problem refers to novel stimuli that are presented which require the organism to emit a novel response. Thus, the novel response required is the solution to the problem, and by definition, a novel response has not been reinforced in the past. Thus, problem solving is typically assessed the first time a complex target response is tested. For instance, students may be trained to calculate the area of a rectangle and a circle as well as word problems involving each separately. They then may be presented with the task of determining the area of a round gazebo and its sidewalk leading to it. In this situation, the students must combine two repertoires which had not previously been combined: calculating the area of a rectangle and calculating the area of a circle. This novel combination constitutes problem solving because there are novel stimuli (combination of a rectangle and circle), plus the behaviors required to produce the solution have never occurred together in such a context. As another example, students trained in number recognition, addition, and subtraction might be asked to solve the problem $2+6-4=$ ? without having been trained in the combination of these skills. Word problems also may involve problem solving when, for instance, students learn the component skills of solving word problems with one kind of operation, are taught a second 
operation, and then are asked to solve a word problem with the new operation. These kinds of outcomes involve both new stimuli and new behavior.

Limitations of research. Although the precision teaching literature claims that ratebuilding procedures produce fluency outcomes, the results have been confounded by the lack of control over variables such as practice and reinforcement rate (Doughty, et al., 2004). Chiesa and Robertson (2000), for instance, examined the use of precision teaching (PT) methods to increase fluency in mathematics. In their procedure, students who were determined to be mathematically slower than their classmates worked on timed probes while the rest of the class participated in the normal activities planned by the teacher. The results indicated that the PT group surpassed their classmates on a post-test that tested composite skills, suggesting that the precision teaching procedures were effective in promoting problem solving. The experimenters, however, failed to account for the amount of practice received by the PT group. The authors reported that the PT subjects did their practice worksheets and timed probes at the same time the control subjects were being taught by their teacher, thus equating the amount of time that both groups were engaged with math problems. It is unclear, however, whether the control subjects were completing worksheets at the same time as the PT subjects or if they were being instructed by the teacher. If the latter, then it is possible that the PT subjects completed more math problems than the control students. Even if both groups completed worksheets at the same time, it is still possible that the PT subjects completed more items simply due to the nature of the timed probes and being instructed to complete as many problems as possible in the time allotted.

Shirley and Pennypacker (1994) attempted to control for the confound between practice and rate building by yoking parallel word lists, one with a rate criterion and the other with only an accuracy criterion. Subjects studied the words on both lists the same number of times; 
however, one list was practiced until subjects reached a rate criterion while the other list was not. Although one subject's retention performance on the rate criterion list was higher than the other list, other subjects did not show this effect, thus clouding the argument that high rates of behavior, not just practice, is critical to producing fluency outcomes such as retention. Resistance to change

Analysis of REAPS. Despite problems attributing fluency outcomes to rate-building techniques, these outcomes represent important educational outcomes and detailed analysis of them might be helpful in identifying procedures that may facilitate them. A behavior analysis of these outcomes suggests that they are examples of resistance to change. All of these outcomes rely on the behavior of interest persisting under a variety of temporal or environmental changes. With retention, subjects engage in the behavior after some time has elapsed since training. In other words, the behavior is resistant to an extended delay between practice and testing. With endurance, the behavior is resistant to the extended temporal duration of testing.

Resistance to change can also account for minimal disruption and application, as these outcomes must occur under changed environmental conditions. Minimal disruption, for instance, requires that the behavior persist with distractions such as noise or visual stimuli present (Mace, et al. 1992). With application, the behavior must persist in the presence of new stimuli that are not discriminative stimuli for the target behavior. Thus, application involves the persistence of behavior when relevant stimuli are imbedded in or compounded with new, irrelevant stimuli. For instance, in the previous example of responding to $2 \mathrm{~h}^{2} \mathrm{j}^{3} \cdot 2 \mathrm{~h}^{3} \mathrm{j}^{2}$, the stimuli have changed from the training stimuli such that there are now two variables instead of only one. This particular stimulus change, however, involves new irrelevant stimuli: the addition of a second variable and 
the change in the variable letter. The discriminative stimuli for the behavior, the multiplication sign and variables raised to a power, remain unchanged.

Resistance to change can account for problem solving in possibly two ways. First, specific component behaviors must persist in order to solve the problem. For instance, the first time students face a problem like $\left(3 \mathrm{x}^{2} \mathrm{y}^{3} \cdot 4 \mathrm{x}^{5} \mathrm{y}^{2}\right)^{2}=$ ?, applying the rules for multiplication of exponents, variables and coefficients, raising variables and coefficients to a power, and order of operations have to persist in order for the student to respond correctly. In other words, the students must engage in each of these operations while disregarding the stimuli that occasion the other operations until it is appropriate to engage in these other operations. A second demonstration of resistance to change that may contribute to problem solving is when a general class of variable behavior is resistant to change. In a problem solving situation, if responding is not reinforced, a variation of responses may occur until reinforcement is obtained. For example, if an answer to the problem above does not result in the correct answer because the student has not learned to apply the order of operations rules, then other variations of multiplying and raising to powers may persist until the correct answer is given. Either or both of these kinds of resistance to change may contribute to problem solving.

Behavioral momentum. Within behavior analysis, resistance to change has been addressed recently as the concept of behavioral momentum. The model for behavioral momentum parallels the model of momentum in physics (Nevin, 1992). In physics, momentum is a function of an object's velocity and mass; the more momentum an object has, the less likely it is to be hampered by an outside force. Nevin applied the model to behavior, likening response rate to velocity and resistance to change as a gauge of the behavior's "mass”. Research has shown that the critical training component for behavioral momentum is reinforcement rate (Dube 
\& McIlvane, 2002; Lattal, 1989; Nevin, 1983). For instance, Dube and Mcllvane (2002) trained subjects on a discrimination task, using either a continuous (CRF) or a variable ratio (VR) schedule of reinforcement. After stability had been observed, the stimuli were reversed and the number of errors measured to determine how resistant to change the behavior was under each schedule. The data showed that subjects made more errors in the reversal component after receiving CRF training than those who received training on a VR schedule. This suggests that the higher rate of reinforcement obtained under the CRF schedule generated more resistance to change than the lower rate of reinforcement under the VR schedule. In other words, subjects' behavior after CRF training continued as originally trained, and did not vary as much in response to the change in contingencies.

Given equally high rates of reinforcement, however, lower response rates are more resistant to change than higher response rates. Lattal (1989) established different response rates by using a fixed ratio (FR) schedule to produce high response rates in one component and a differential reinforcement of low rate (DRL) schedule of reinforcement to produce low rates of responding in another component. The overall rate of reinforcement, however, was equal on both schedules. Once stability was observed in this baseline condition, response-independent food was introduced as a disruptor. During these disruption conditions, responding in the FR component decreased more than responding in the DRL component compared to their respective baseline rates. These results suggest that given equal rates of reinforcement during baseline, lower response rates are more resistant to change than higher response rates.

The findings from the behavioral momentum literature suggest that further investigation of the practices of precision teaching is warranted. The precision teaching literature emphasizes the relation between high rates of responding and the outcomes of fluency. As described above, 
however, these outcomes can all be described in terms of resistance to change, and the basic research on resistance to change from the perspective of behavioral momentum has shown that high rate of reinforcement is the critical factor for producing resistance to change. If it is the high rate of reinforcement that produces fluency, then high rate of responding may not be a necessary feature of precision teaching. Moreover, investigating the relation between precision teaching and behavioral momentum may assist in understanding the relation between resistance to change and stimulus changes such as those found in application and problem solving.

\section{Statement of the Problem}

The methods used by precision teachers to achieve fluency, namely building high rates of responding with high rates of reinforcement, and the research on behavioral momentum lead to questions regarding what aspects of precision teaching result in the outcomes of fluency. On one hand, precision teaching literature suggests that the high rates of responding produce these outcomes. On the other hand, behavioral momentum research suggests that high reinforcement rates should produce these outcomes. The confounding of these variables in the typical precision teaching procedures makes it unclear which variables are responsible for fluency. In addition, some evidence in the behavioral momentum literature suggests that when reinforcement rate is held constant, lower rates of responding are more resistant to change.

The purpose of the proposed study, then, was to investigate the role of high rates of reinforcement used in precision teaching in producing the behaviors necessary for minimal disruption, application, and problem solving to occur. In each condition, response rates were controlled while the rates for purported reinforcement were varied. To test for disruption, subjects were asked to engage in the trained responses while being exposed to distracting noises. The tests for application involved engaging in the trained responses in the presence of new 
stimuli as done in Mayfield and Chase (2002), and the problem-solving tests required untrained combinations of individually-trained responses. Varying the reinforcement rate would allow for assessment regarding whether reinforcement rate is the critical component of precision teaching that specifically decreases disruption and facilitates application and problem solving.

Method

Subjects

Twelve female West Virginia University students who have not taken college level Algebra nor passed Trigonometry, Pre-Calculus, or Calculus in high school participated in the study. Subjects met the criteria specified below under pretesting. Subjects were recruited from undergraduate psychology classes and received extra credit as well as monetary reimbursement for their participation. Subjects signed an informed consent form (Appendix A) prior to their participation.

Setting, Apparatus, and Materials

Sessions were conducted in a cubicle measuring approximately 2 meters x 2 meters. In the cubicle, subjects were provided a desk, chair, headphones, and a computer. During the session, the experimenter remained in an adjacent control room to observe the subject through a $0.5 \mathrm{~m}$ x 1.15 m one-way mirror. A computer monitor in the control room also allowed for observation of the subjects' responses during the basic pretest and training (described below) by displaying the same screen as the subject's computer. The experimenter used this monitor to determine the feedback given to the subjects regarding their performance during training. The computer screens displayed the math rules, examples, and practice items during training, as well as the most recent total number of points earned that was reported to the subject. The experimenter and subjects interacted via a $30 \mathrm{~cm}$ x $30 \mathrm{~cm}$ wooden door. The experimenter 
provided verbal feedback through this door, and tests were passed through the door as well. The computer interface was programmed using Microsoft Visual Basic 6.0. Scrap paper was provided for the subjects to use.

Procedures

The experiment involved five phases, or steps. These steps are outlined in Table 1 and are described below.

Pretesting. Subjects were given a series of pretests to determine their eligibility for the study. The first test (basic pretest - See Appendix B) was a test of basic math skills like that used in Kim (2003). This test included 50 addition, subtraction, multiplication, and division items that sometimes included variables, exponents, or radicals. Individual items on the basic pretest did not use multiple operations, nor did they combine variables, exponents, and radicals within a single item. Items were presented on the computer, with 4 multiple-choice answers available for each item. Subjects were required to score at least $80 \%$ on the basic pretest within $400 \mathrm{~s}$, otherwise they were paid, given a participation slip to receive extra credit, and dismissed from the study. The rate criteria were used to ensure that subjects were fluent with the basic skills, as this fluency may have affected subsequent responding on the rules to be trained. Rate criteria were based on the performance of 4 "experts": math majors who had completed at least Calculus I. Measures were taken on how long it took experts to complete the basic skills test with at least 90\% accuracy. The test was administered 3 times, and the mean for the experts was $369 \mathrm{~s}$. The time criterion for the subjects was subsequently increased to $400 \mathrm{~s}$, and the accuracy criterion was decreased to $80 \%$ to accommodate for more potential subjects. Subjects were given at least 3 attempts at the basic pretest. If subjects did not meet both the rate and accuracy criteria within these 3 attempts or showed no improvements on either criteria, they were dismissed. If subjects 
continued beyond three attempts, however, any lack of improvement between tests was grounds for dismissal.

After passing the basic math skills pretest, participants completed a 25-question pretest on exponent skills (exponent pretest —See Appendix C) similar to the one used in Kim (2003). This pretest consisted of 5 items from each rule, and was given to ensure that subjects were not already proficient in the skills to be trained in the study. This pretest was administered on paper because subjects' rate of performance was not a critical factor on this task. Subjects were required to score $20 \%$ or less on the exponent pretest in order to continue in the study. If subjects scored higher than $20 \%$ on the exponent pretest, they were dismissed from the study. Subjects who scored $20 \%$ or less were then given an application pretest (See Appendix D).

The application pretest was similar to the exponent skills pretest except that it was a 12item test that had multiple variables incorporated into each item. If subjects scored higher than $50 \%$ on the application pretest, they were dismissed as described previously. If subjects scored $50 \%$ or lower on the application pretest, however, they were given the problem solving pretest (Appendix E). The problem solving pretest contained 12 items that incorporated multiple operations and rules within each item. Subjects who answered any of the problem-solving problems correctly were dismissed. Those who did not answer any of these items correctly were selected to continue in the study.

Training conditions. Individual sessions were conducted approximately 5 times per week and lasted approximately $1 \mathrm{hr}$ each. Subjects received general instructions (Appendix F) regarding training or testing procedures prior to the session. Subjects were exposed to either high or low reinforcement rates. In the High Reinforcement (HR) group, subjects were provided points and feedback on their performance after each 1-min timing, or once every min. For the 
Low Reinforcement (LR) group, subjects were provided points and feedback on their performance after every fifth 1-min timing, or once every 5 min. These values were chosen because they exceed the typical ratio for schedule parameters in the behavioral momentum literature, which is usually 1:4 (e.g., Dube \& Mcllvane, 2002; The instructions on the screen for all training tasks read:

\section{Welcome to our Lab!}

You will be given a math skill to learn. A rule for each skill will be provided as well as examples demonstrating the rule. You will then be given a series of items using the rule. Complete as many items as you can correctly to earn maximum points. To earn the most points in the least amount of time, you must answer the questions with at least 90\% accuracy AND at the target rate for this rule (13 problems per minute). If you do, you will earn 5 points. You must perform at this rate on 5 timings to complete training on this rule. If you reach the target rate on 5 timings within the first session of a rule, you will earn a $\$ 1.00$ bonus for that rule.

If you do not meet the target rate, however, then you will begin a new timing, and you will earn 1 point each time you improve upon your best previous performance for this rule by $1.25 \mathrm{x}$ with at least $90 \%$ accuracy. For example, if your best performance at 90\% accuracy was 8 questions, you must answer at least 10 questions with 90\% accuracy on the next timing to earn 1 point.

You will earn 5 cents per point. Worksheets have been provided if you need to work out the answer. When the timing is over, knock on the wooden door and the experimenter will review your answers with you. If you have no further questions, please put on the headphones and click the button below to continue. 
The 1.25x criteria for improvement was selected on the basis of a minimum acceleration criterion described by White and Haring (1980), who reported that an acceleration rate $\geq 1.25 \mathrm{x}$ is the minimum acceleration rate accepted by precision teachers. For instance, subjects complete 8 problems/min during a timing, then they must complete at least 10 problems/min with $90 \%$ accuracy during the next timing in order to receive points.

The rate criterion for each rule was also based on the 4 math major experts who were tested prior to the experiment. In this case, the first three timings for each rule in which they reached at least $90 \%$ accuracy were recorded. The mean of these recorded timings was 13 per minute, which was used as the rate criterion for all 5 rules.

Subjects put on the headphones before beginning and wore them throughout training. During training, only white noise was delivered through the headphones. Subjects were trained on each skill individually. Initially, a rule concerning each skill was presented on the computer screen along with examples (Appendix G). A mouse click on a button at the bottom of the screen advanced the screen to a series of items using that rule that were arranged in worksheet format to facilitate high rate of responding (Oddsson \& Chase, 1999). To facilitate scoring and recording, subjects were required to choose their answer to each item from a set of four multiplechoice answers on the computer (Appendix H). The appropriate selection was made by clicking on the corresponding button; once a selection had been made, the answer could not be changed. Subjects were provided with scrap paper to work out problems, if necessary. Subjects were trained on 5 different skills through the course of the study: 1) multiplying exponents, 2) dividing exponents, 3) raising exponents to a power, 4) finding the roots of exponents, and 5) order of operations. 
Subjects in both conditions were required to achieve an accuracy rate of $90 \%$ to receive points. If subjects met the terminal rate of 13 correct/min with $90 \%$ accuracy, they received 5 points. If they did not reach the terminal rate, they could still earn 1 point by improving on their best previous performance by $1.25 \mathrm{x}$ while still maintaining $90 \%$ accuracy.

After subjects completed their timing(s), the incorrect answers were highlighted on each form, and the experimenter reviewed the incorrect items with the subject and provided feedback by informing the subject of how to achieve the correct answer. For example, if subjects solved the problem $3^{2} h^{3} \cdot 3^{5} h^{2}=9^{7} h^{5}$, feedback was: "The coefficients in this problem are the same, so you don't multiply them. Instead, you keep the coefficient and just add the exponents. So you should have $3^{7} h^{5}$." To emulate other feedback that may be incorporated in a natural classroom setting, subjects were also provided feedback such as "Good job” and "Your accuracy is good, so just try to get faster now.” All feedback was provided through the wooden door described previously. When the subject knocked on the door to review answers, the experimenter would refer at the monitor in the control room to give feedback. If subjects failed to meet the terminal criteria for a rule and did not show improvement in 3 sessions, they were dismissed from the study.

Subjects continued the timings until the terminal rate aims were met. Subjects in both groups were required to perform at the terminal rate on 5 separate 1-min timings, although it was not necessary for these timings to occur consecutively. HR subjects were told whether or not they achieved the required accuracy and acceleration criteria after each timing, while subjects in the LR group were only be given feedback on their performance after every fifth timing. Thus, HR subjects were told whether they reached the criterion once a minute and LR subjects were told how many times they reached the accuracy and acceleration criteria once every 5 minutes. 
The same amount of feedback was given for correct and incorrect performance regardless of the group, although the dispersion of feedback was different between the groups. For example, if subjects answered 3 questions incorrectly on a worksheet, they would receive feedback for each incorrect performance regardless of whether they were in the HR or LR group. The only difference would be that the HR subject would receive that feedback every minute, whereas the LR subject would receive the feedback every five minutes. If subjects reached the terminal rate aim on a skill, they received 5 points. Subjects in the HR group continued until either the terminal rate had been reached on 5 timings or they completed 15 timings, whichever came first. Subjects in the LR group continued until the end of the block of 5 timings on which they reached the criteria for the $5^{\text {th }}$ time or until they completed 15 timings, whichever came first. The most current point total reported to the subject was displayed on the computer screen throughout training.

Disruption tests. Tests were administered the session after subjects had completed their training on a rule. All tests were given on paper, rather than on the screen, in order to better use constructed response items rather than multiple-choice items. The first test was the disruption test. Prior to the start of the disruption test, the experimenter would give the following instructions:

This is the first test for Rule _. You should recognize the problems on the test. You will earn 7 cents for each correct answer, and there is a 2-cent penalty for incorrect answers on this test. There is no time limit for this test, so you can take as much time as you need. There is scrap paper if you want to use it. Please note that you do not have to simplify exponents; for example, if you have an answer that is $2^{8}$, you can leave it like that - you do not have to calculate it out. Please make sure you wear the headphones; there may be 
something different coming from them, but that is normal. When you are finished, knock on the wooden door and pass the test through. Do you have any questions?

The disruption tests consisted of 25 problems, and subjects could take as much time as needed to complete the items, although the time was recorded as a dependent measure. No feedback was given during any testing condition regarding how to solve the problem. To test subjects for disruption, or resistance to distraction, a recording of the experimenter reciting coefficients, variables, and exponents that did not correspond with the test items was played through the headphones. Subjects were alerted to the change from white noise to these potential distruptors to circumvent their reporting the change. There were 5 different disruption tests, one test per rule (See Appendix I).

Application tests. Following the disruption test, subjects were given an application test. The experimenter gave the following instructions for the application test:

This is the second test for this rule. It's a little different from the first one; you may recognize some problems on here, and you may not recognize some others, but there is no penalty for incorrect answers. There is no time limit for this test, so you may take as much time as you need to. There's scrap paper there if you need it. Wear the headphones for white noise, and when you are finished, knock on the wooden door and pass the test through. Do you have any questions?

As in the disruption tests, there were 25 questions, and subjects had as much time as needed to complete the items. Again, the time was recorded as a dependent measure. The application tests assessed the subjects' use of each individual rule, with each question involving multiple instances of a single rule within an item. In other words, whereas the training worksheets and disruption tests had problems involving only one variable, such as $3 h^{3} \cdot 2 h^{2}$, the 
application test items contained problems such as $2 h^{5} j^{2} \cdot 5 h^{2} j^{4}$. There were 5 parallel versions of the application test with similar items in each version (Appendix J). There were 5 questions per rule on the application tests. White noise was played through the headphones during this testing phase.

Problem-solving tests. The third test was for problem solving, which assessed whether subjects could combine individual rules without receiving specific training in doing so. For instance, a problem-solving item might be $\left(2 h^{2} \cdot 2 h^{5}\right)^{4}$, which involves combining 3 rules: order of operations, multiplying coefficients and variables with exponents, and raising variables and exponents to a power. Because subjects had not been trained to combine these rules, they may be used as measures of problem solving. Instructions for problem solving were as follows:

This is the last test for this rule. It's a little different from the first two; you may recognize some problems on here, and you may not recognize some others, but there is no penalty for incorrect answers. There is no time limit for this test, so you may take as much time as you need to. There's scrap paper there if you need it. Wear the headphones for white noise, and when you are finished, knock on the wooden door and pass the test through. Do you have any questions?

Again, there were 5 parallel versions of the test, with 25 questions (Appendix K). There were 8 items each combining 3 and 4 rules, and 9 items combining all 5 rules. Subjects had as much time as necessary to complete the items. With the problem-solving tests, items involving all of the rules were included regardless of whether the rule had been trained or not. By doing so, it could be determined if exposure to novel stimuli alone was enough to result in combining rules as necessary to engage in problem solving. As with the application testing, white noise was played through the headphones during testing. 
Retention tests. Approximately 2 weeks after completing the tests for Rule 5, subjects returned to take a retention test. This interval was chosen because other studies have shown that a 2-week interval is sufficiently sensitive to observe differential effects (e.g., Oddsson, 1998; Kim, 2003). The retention test was a combination of both application and problem-solving items. Subjects were given two 25-question tests. The first 25-item test was an application test with 5 items per rule. The second test consisted of 25 items, including 8 problem-solving items each for combinations of 3 and 4 rules, and 9 problem-solving items combining all 5 rules. The experimenter's instructions for each retention test were:

This test uses rules you have already learned. Answer as many problems as you can. You will earn 7 cents for each correct answer and will be penalized 2 cents for each incorrect answer. You do not have to simplify your answers, so if the answer is $2^{8}$, you may leave it as that; you do not have to simplify it. There is no time limit, so you can take as much time as you need. There is scrap paper there if you need it. Wear the headphones for white noise, and when you are finished, knock on the wooden door and pass the test through. Do you have any questions?

As with the other tests, the time to completion was recorded for each test. White noise was played through the headphones during both tests.

Reinforcement procedures. Subjects earned 7 cents for each correct answer on all tests including the basic and exponent pretests, and were penalized 2 cents for any incorrect answers on the disruption and retention tests. The penalty was established as a deterrent to rushing through the items. It was not imposed during application and problem solving tests 1-4 because these tests included items that the subjects had not been trained to answer and it seemed unfair to penalize them.. The final application and problem solving tests (after rule 5) also did not have the 
penalty in order to keep it parallel to the other tests. During training, subjects earned 5 cents per point and a $\$ 1.00$ bonus if they completed training during the first session for that rule. If subjects failed to complete training during the first session for the rule, they continued to earn points as described above, but were not eligible to receive the bonus for that rule. Subjects were paid halfway through the study and again at the end of the study. Each day, subjects were given a record of their earnings for the day. Furthermore, subjects who completed the study and attended every scheduled session received a $\$ 1.00$ bonus for every session attended, payable at the end of the study. Subjects will also received extra credit in their psychology class for their participation. Interobserver agreement.

Interobserver agreement (IOA) for accuracy of responding was calculated on approximately $21 \%$ of the tests. Agreement scores were calculated by dividing the number of agreements by the sum of agreements and disagreements and then multiplied by $100 \%$ to reach a percentage agreement. The average IOA score was $99 \%$. IOA on time data was conducted to ensure that the time that elapsed between presenting the test to the subject and the start of the timer was equal in both groups. A second observer began the timer when the experimenter shut the door after giving the test to the subject, and stopped the timer when the subject knocked on the wooden door. The experimenter began her own timer when she returned to the control room, and stopped it when the subject knocked on the wooden door. Approximately $12 \%$ of the tests had time IOA data. A $t$-test indicated that there was no difference in the time differential between the HR and LR groups, with the average differential being approximately $5.68 \mathrm{~s}$. 


\section{Results}

\section{Pretests}

A one-way analysis of variance (ANOVA) was conducted on accuracy and rate measures for each of the pretests to ensure that no differences existed between the HR and LR groups prior to training. An alpha level of 0.05 was used for all analyses. The ANOVAs indicated that there were no significant differences between the groups on any of the pretest measures. For the problem solving pretest, an ANOVA was conducted on time data rather than rate data because all percentages and rates were zero due to the requirement that subjects must not have answered any of the problem solving questions correctly.

\section{Training}

Figure 1 shows the means and standard errors for the number of timings required to reach the terminal criteria for each rule. A 2 x 5 mixed design ANOVA with a between-group factor of reinforcement rate (HR, LR) and a within-group factor of rule (Rules 1-5) was conducted to evaluate the number of timings needed to reach the terminal criteria. The ANOVA indicated that there was no interaction between rule and reinforcement rate, nor was there a main effect of reinforcement rate. There was a main effect of rule on the number of timings to reach the terminal criteria, however, $F(4,40)=14.85$, $\mathrm{p}<0.001$. Pairwise comparisons using a Bonferroni adjustment for multiple comparisons indicated that it took longer to complete training on Rule 1 $(M=28.75, S E=3.01)$ than on Rule $2(\mathrm{M}=9.42$, SE 0.86), $\mathrm{p}<0.001$, Rule $3(M=8.91, S E=$ 0.97), $\mathrm{p}<0.001$, and Rule $4(M=9.83, S E=1.68), \mathrm{p}=0.002$. Training on Rule $5(M=44.92$, $S E=8.94$ ) also took significantly longer to complete than Rule 2, $p=0.029$, Rule $3, p=0.024$, and Rule 4, p = 0.036. Rule 1 was not significantly different from Rule 5, however. These results suggest that there were no systematic differences between the groups regarding the amount of 
practice obtained on the rules, but there were statistical differences between rules involving the number of timings required to reach the terminal criteria on a rule.

Experimenter-designed tests

The primary dependent variables in this study were accuracy and rate on the experimenter-designed distraction, application, and problem-solving tests. Tables 2, 3, and 4 list the accuracy and rate data for all subjects on these tests. Both measures were evaluated using $2 \mathrm{x}$ 5 mixed ANOVAs with a between-group factor of reinforcement rate (HR and LR) and a withingroup factor of repeated testing (Tests 1-5). For all analyses, Test 1 refers to the test administered after completion of training on Rule 1. One HR subject was missing time data for the first application and problem solving test, so the data were estimated using a method proposed by Winer, Brown, and Michels (1991) that uses data from adjacent cells to estimate the missing points. Time data from Application Test 1 and Problem Solving Test 1 were taken from two randomly chosen HR subjects to serve as the adjacent cell data. The following equation was used to estimate the time value:

$$
\frac{u_{a, 1}}{t_{a, 2}}=\frac{\left(t_{b, 1} / t_{b, 2}\right)+\left(t_{c, 1} / t_{c, 2}\right)}{2}
$$

In this equation, $u_{a, 1}$ refers to the missing value for Subject A on Test $1, t$ denotes time data, the subscript letter refers to the subject, and the subscript number refers to the test number.

Distraction tests. Figure 2 shows the group means and standard errors for the percent correct on each distraction test. An ANOVA was conducted to evaluate accuracy on the distraction tests. There was no significant interaction between reinforcement rate and repeated distraction testing, nor was there a significant main effect of reinforcement rate on accuracy for these tests. There also was no significant main effect of repeated testing. 
An ANOVA was also conducted on the rate data for the distraction tests. Figure 3 shows the group means and standard errors for the number of correct responses per minute for the distraction tests. Again, no significant interaction for rates was found between reinforcement rate and repeated testing, and no main effect was found for the reinforcement rates. There was, however, a main effect of repeated testing, $F(4,40)=3.60, \mathrm{p}=0.013$. Pairwise comparisons using a Bonferroni adjustment for multiple comparisons indicated that the number of correct responses per minute made on Test $5(M=3.79, S E=0.45)$ was significantly less than the rate for Test $4(M=5.55, S E=0.82), \mathrm{p}=0.046$. No other pairwise comparisons were significant.

Application tests. Figure 4 shows the group means and standard errors for accuracy on the application tests. The ANOVA assessing the accuracy on the application tests showed no interaction between reinforcement rate and repeated testing and no main effect of reinforcement rate. There was, however, a main effect for repeated testing, $F(4,40)=22.93$, p $<0.001$. Pairwise comparisons using a Bonferroni adjustment for multiple comparisons indicated that the accuracy on Test $1(M=44.33, S E=4.88)$ was significantly lower than that of Test $3(M=75$, $S E=2.93), \mathrm{p}=0.001$, Test $4(M=84, S E=5.12), \mathrm{p}=<0.001$, and Test $5(M=81.67, S E=$ 5.55), $\mathrm{p}=0.002$. Rule 2 accuracy $(M=53, S E=3.54)$ was also significantly lower than that of Tests $3, \mathrm{p}=0.001,4, \mathrm{p}=0.002$, and $5, \mathrm{p}=0.005$. There were no differences between Tests 1 and 2, and no other comparisons were significant.

Rates for the application test were also assessed using an ANOVA; the means are shown in Figure 5 with standard error bars. There was no significant interaction between reinforcement rate and repeated testing, nor was there a main effect of reinforcement rate. A main effect of repeated testing was found, $F(4,40)=21.31, \mathrm{p}<0.001$, with pairwise comparisons using a Bonferroni adjustment showing that rates on Test $1(M=1.26, S E=0.13)$ were significantly 
lower than rates on Test $3(M=2.93, S E=0.32), \mathrm{p}=0.001$, Test $4(M=3.42, S E=0.42), \mathrm{p}=$ 0.001 , and Test $5(M=3.29, S E=0.32), \mathrm{p}<0.001$. Rates for Test $2(M=1.79, S E=0.19)$ were also significantly slower than those for Tests $3, \mathrm{p}=0.014,4, \mathrm{p}=0.004$, and 5, $\mathrm{p}=0.004$. Again, there were no differences between Tests 1 and 2, and no other significant comparisons were found.

Problem solving tests. Figure 6 shows the mean accuracy, with standard error bars, on the problem solving tests for each group. The ANOVA evaluating accuracy on the problem solving tests determined that there were no significant interaction between reinforcement rate and repeated testing, nor was there any main effect of reinforcement rate. Like the Application accuracy tests, there was a significant main effect of repeated testing, $F(4,40)=13.25, \mathrm{p}<$ 0.001. Pairwise comparisons using a Bonferroni adjustment for multiple comparisons indicated that the accuracy on Test $1(M=6.67, S E=4.39)$ was significantly lower than the accuracy on Test $4(M=46, S E=10.39), \mathrm{p}=0.01$, and Test $5(M=46.33, S E=9.54), \mathrm{p}=0.004$. Test 2 accuracy $(M=5, S E=2.26)$ was also significantly lower than Test $4, \mathrm{p}=0.034$, and Test $5, \mathrm{p}=$ 0.015. Accuracy on Test $3(M=15.67, S E=6.53)$ was also significantly lower than Test $4, \mathrm{p}=$ 0.047, and Test 5, $\mathrm{p}=0.048$. Performance on Tests 4 and 5 was not significantly different, however, nor were the differences between Tests 1, 2, and 3.

The rate data for the problem solving tests also were assessed; Figure 7 shows mean number of correct responses per minute for each problem solving test. An ANOVA performed on rates for the problem solving tests yielded no interaction effects between reinforcement rate and repeated testing, nor did it yield a main effect for reinforcement rate. Similar to the rate data for the other tests, there was a significant main effect for repeated testing, $F(4,40)=14, \mathrm{p}<$ 0.001. Pairwise comparisons indicated that the rate of correct responding on Test 1 ( $M=0.069$, 
$S E=0.04)$ was lower than rates on Test $4(M=0.61, S E=0.12), \mathrm{p}=0.006$, and Test $5(M=$ $0.61, S E=0.12), \mathrm{p}=0.003$. The rate for Test $2(M=0.065, S E=0.03)$ was also significantly lower than rates for Test 4, $\mathrm{p}=0.019$, and Test $5, \mathrm{p}=0.011$. No other significant comparisons were found.

Retention tests. Figure 8 shows the mean accuracy, with standard error bars, for accuracy on the application and problem solving tests. A one-way ANOVA yielded no significant differences on accuracy between the HR and LR groups for either the application test or the problem solving test. Figure 9 shows the groups' means for rates on both tests. There were also no differences found between the groups' response rates on either the application test or the problem solving test.

\section{Discussion}

The results of this study suggest that reinforcement rates do not differentially affect testing under distraction conditions, nor does it affect application, problem solving, or retention. Any conclusions drawn from the current data, however, should be tempered considering the lack of power due to a small $n$ and extreme variability on some of the measures. It is possible that increasing the number of subjects and decreasing variability within groups through alternative procedures could yield differences between high and low rates of reinforcement. The rest of this discussion addresses changes that could be made to potentially decrease within group variability while still testing the effect of rate of reinforcement on the outcomes of fluency.

One recurring problem in the current study was the inability to recruit subjects who qualified for the study. The standards were relaxed from those originally planned to allow for a larger pool of qualified applicants. Most of these adjustments came in the way of allowing worse performers to be included in the potential pool. The standards used in the present study closely 
parallel those used previously, but the relaxation of inclusion criteria likely contributed to the wide variability in the data. Future research could retain the stricter standards of inclusion so that only subjects who are proficient with basic skills would be included. Another option would be to isolate basic skills that are deficient, and train them to fluency before beginning training on the algebra skills. Identifying deficient skills and training them before moving on to other more complex skills is a cornerstone of precision teaching, and will be discussed in more detail later. Many of the training procedures of the current experiment were based on two previous studies that have shown the effect of behavioral training on fluency outcomes (Mayfield \& Chase, 2002; Kim, 2003). One procedure used in both of these studies that has yielded reduced within-group variability is cumulative review. Cumulative review was defined as the inclusion of all previously-trained skills during review sessions. Both studies found that cumulative reviews facilitated the use of the trained skills on application and problem solving tests, particularly when the review items were intermixed, rather than being arranged homogenously in a series (Kim). Kim also found that cumulative review with intermixed items facilitated problem solving performance on retention tests, particularly with subjects who had scored the lowest on pretest measures. Due to the demonstrated effectiveness of cumulative review in producing application, problem solving, and retention, it was not included in the current study because it was predicted that cumulative review would produce a ceiling effect. Given the poor and variable performance on the application and problem-solving tests, however, perhaps future studies should include a cumulative review.

The current study also differed from Mayfield and Chase (2002) and Kim (2003) in several other ways. One of these changes was the incorporation of computerized multiple-choice training. The current study computerized the training materials to control the variable of interest, 
which was reinforcement rate. The computerized training program provided multiple choice answers during training, but required constructed answers during testing. Mayfield and Chase and Kim, in contrast, required constructed answers during both training and testing. The differences between the kind of responding required in training and testing in the current experiment may have contributed to the failure to find differences between the groups. Previous research has suggested that performance on constructed-response tests is enhanced when training also occurs using a constructed-response format rather than a multiple-choice format (Williams, 1969). The effect is particularly pronounced when testing for more technical and unfamiliar repertoires, as is arguably the case with the skills trained in the current study. Furthermore, low aptitude students have shown higher gains when trained using a constructed-response format (Tobias \& Inger, 1976), and the fact that all subjects in this study were low performers on these skills likely compounded the problems posed by the training and testing formats. These results suggest that a multiple-choice training format, which provides the required information (i.e., the solution), is not the ideal format by which to train low performers. Based on the studies regarding training and test format, and because reinforcement rate is best controlled automatically, future research should attempt to develop a training procedure that allows constructed responding to occur while maintaining control of the rate of reinforcement.

Requiring students to perform both training and testing in the same format (e.g., computerized multiple-choice format vs. constructed responding) would also allow for more parallels to be drawn between this preparation and other studies in the behavioral momentum literature. In a standard behavioral momentum procedure, disruption or resistance to change is assessed by comparing a performance (e.g., button pressing) that is subject to disruptors (e.g., extinction) to baseline performance of that same behavior. Under the current procedure, 
responding during distraction tests could not be compared to baseline rates during training because training and testing require two different kinds of responding. For instance, if training were changed so that baseline responding involved the same constructed responses as the test responding, then disruption during the distraction tests could be assessed by looking at response rates during the tests as a proportion of the baseline response rates obtained during training. This change would more closely align with measures of disruption in the typical behavioral momentum study that have been sensitive to differences in reinforcement rate.

Although most behavioral momentum studies use non-human animals engaging in simple responses like lever pressing, to which "incorrect" responding is never calculated, there remains some evidence to suggest that the accuracy of responding in more complex tasks is affected by reinforcement rate. Dube and McIlvane’s (2002) study with simple discriminations suggested that higher reinforcement rates lead to more persistence with the originally-trained responses during distraction conditions. In their study, subjects who received a higher reinforcement rate during baseline continued to respond according to the original baseline discriminations despite the introduction of reversed discriminations as a disruptor. In the context of the present study, using the same format for training and testing would allow comparisons to be made for accuracy of responding as well as for rate of correct responding.

In addition to utilizing constructed responding, considerations also should be made regarding the current procedure and its parallels to precision teaching. One premise of precision teaching is that the targeted fluency outcomes are determined a priori. The current study used one method for doing this; it tested high-level math students to determine the "expert" criteria. These subjects, however, were not tested on any of the outcome measures of fluency (e.g., retention, application, distraction, and problem solving) to determine their level of proficiency in 
using the component skills. It is possible, then, that their level of performance on tests of these outcomes would not have reached a satisfactory level (e.g., 90\% proficiency), and thus their performance on component tasks would not be considered "expert" performance. Based on this analysis, it is possible that the 13 problems/min target response rate derived from the mean rate of these "experts" was too low, and perhaps a higher rate requirement was necessary to produce the level of proficiency with component skills required to engage in more complex tasks such as application and problem solving.

Related to the seemingly "low" rate requirements is the observation that the skills taught in the current experiment are actually composite tasks comprised of smaller component tasks. For example, the answer to $3 h^{3} \cdot 2 h^{2}=$ is $6 h^{5}$, which requires multiplication of the coefficients, carryover of the variable, and addition of the exponents. The answer to the problem, then, may be construed as 3 separate responses: the coefficient 6 , the variable $h$, and the exponent 5 . Given the low rate of 13/min required and the poor performance on some of the tests of fluency, perhaps these more finite component skills need to be trained further and to higher rates. Precision teachers might suggest breaking down the composite task into its components, such that someone who answered $5 h^{5}$ needs to be trained on multiplication of coefficients. After all component tasks are mastered, then, high performance on composite tasks should emerge. Identifying these component tasks, however, would require the use of constructed responding to provide more information regarding any dysfluencies that may need to be targeted for additional training. Thus, in addition to the previously mentioned benefits of constructed responding, a constructed-response training format would also serve the interests of precision teaching regarding component-composite analyses. 
Another difference between the current procedure and that of the precision teaching literature concerns the parameters of the reinforcement schedules used. In many instances, precision teaching methods have been shown to be more effective in comparison to normal classroom procedures (e.g., Chiesa \& Robertson, 2000). Feedback on a given task in a normal classroom setting often occurs much less frequently than feedback given by teachers using precision teaching .For instance, consider the common situation in a typical classroom that children do homework Monday night, submit it Tuesday, and do not get any feedback on their performance until Wednesday. When using one-minute timings, precision teaching provides feedback every minute, and thus operates on an exponentially richer schedule than that of a typical classroom. Therefore, it is possible that the parameters used in the current study do not provide sufficient discrepancy in reinforcement rates to produce the differences often seen between precision teaching methods and their normal curriculum counterparts. Although the current study's 1:5 parameter ratio exceeds the 1:4 ratio often used in behavioral momentum literature (e.g., Nevin \& Grace, 1999; Dube \& McIlvane, 2002), the responses for many behavioral momentum studies are typically simple responses such as lever presses or key pecks. Thus, it is possible that more complex responses may require a higher ratio discrepancy to produce the differences observed between responding maintained by different reinforcement rates.

\section{Conclusion}

Although the results of the present study do not support the conceptualization of fluency outcomes in terms of rate of reinforcement, there are several procedural factors that differed from the typical preparations for both a behavioral momentum study and a precision teaching procedure that may have affected the outcome. Based on what we know about contingencies of 
reinforcement, the conceptualization proposed herein remains a possibility. Results from the behavioral momentum literature strongly support the role of reinforcement rate in resistance to change, as measured by not only rate of responding but by accuracy as well. High performance on measures of rate and accuracy are also predicted by precision teaching, which utilizes frequent timed probes to monitor learning trends. These probes ostensibly result in reinforcement, thus the higher rates of reinforcement in a precision teaching model, as compared to a regular classroom model, should produce more resistance to change. The similarities between the results of these two literatures should not be ignored, and steps should be taken to correct some of the procedural problems of the current study to further examine their relation. Further investigations in this area hopefully will yield a parsimonious behavioral account of fluency, which in turn may instruct future arrangements of classroom contingencies to produce these behavioral outcomes. 


\section{References}

Binder, C. (1996). Behavioral Fluency: Evolution of a New Paradigm. The Behavior Analyst, 19(2), 163-197.

Binder, C. (2004). A refocus on response-rate measurement: Comment on Doughty, Chase, and O’Shields (2004). The Behavior Analyst, 27, 281-86.

Binder, C., Haughton, E., \& VanEyk, D. (1990). Increasing endurance by building fluency: Precision teaching attention span. Teaching Exceptional Children, 22(3), 24-27.

Chase, P. N. (2003). Behavioral education: Pragmatic answers to questions about novelty and efficiency. In K. A. Lattal and P. N. Chase (Eds.), Behavior Theory and Philosophy (pp. 347-367). New York: Kluwer Academic/Plenum Publishers.

Chiesa, M., \& Robertson, A. (2000). Precision Teaching and Fluency Training: making maths easier for pupils and teachers. Educational Psychology in Practice, 16(3), 297-310.

Doughty, S. S., Chase, P. N., \& O’Shields, E. M. (2004). Effects of rate building on fluent performance: A review and commentary. The Behavior Analyst, 27, 7-23.

Dube, W.V., \& McIlvane, W.J. (2002). Reinforcer rate and stimulus control in discrimination reversal learning. The Psychological Record, 52, 405-416.

Howell, K.W., \& Lorson-Howell, K.A. (1990). What's the hurry?: Fluency in the classroom. Teaching Exceptional Children, 22(3), 20-23.

Kim, C. (2003). Response variability through cumulative review: Applications to mathematical problem solving. Unpublished doctoral dissertation, West Virginia University.

Lattal, K.A. (1989). Contingencies on response rate and resistance to change. Learning and Motivation, 20, 191-203. 
Mace, F. C., Lalli, J. S., Shea, M. C., Lalli, E. P., West, B. J., Roberts, M., \& Nevin, J. A. (1992). The momentum of behavior in a natural setting. Journal of the Experimental Analysis of Behavior, 54, 163-172.

Mayfield, K.H., \& Chase, P.N. (2002). The effects of cumulative practice on mathematics problem solving. Journal of Applied Behavior Analysis, 35, 105-123.

Neef, N. A., Nelles, D. E., Iwata, B. A., \& Page, T. J. (2003). Analysis of precurrent skills in solving mathematics story problems. Journal of Applied Behavior Analysis, 36, 21-33.

Nevin, J.A. (1992). An integrative model for the study of behavioral momentum. Journal of the Experimental Analysis of Behavior, 57, 301-316.

Nevin, J. A., \& Grace, R. C. (1999). Does the context of reinforcement affect resistance to change? Journal of Experimental Psychology: Animal Behavior Processes, 25, 256-268.

Nevin, J.A., Mandell, C., \& Atak, J.R. (1983). The analysis of behavioral momentum. Journal of the Experimental Analysis of Behavior, 39, 49-59.

Oddsson, F. (1998). Fluency and controlled-operant training methods. Unpublished master's thesis, West Virginia University.

Oddsson, F., \& Chase, P. N. Fluency training with computerized voice recognition training methods. Presented at the Association for Behavior Analysis, Chicago, May 1999.

Shahan, T. A., \& Chase, P. N. (2002). Novelty, stimulus control, and operant variability. The Behavior Analyst, 25, 175-190.

Shirley, M. J., \& Pennypacker, H. S. (1994). The effects of performance criteria on learning and retention of spelling words. Journal of Precision Teaching, 12, 73-86.

Skinner, B. F. (1969). Contingencies of reinforcement: A theoretical analysis. Englewood Cliffs, NJ: Prentice Hall. 
Tobias, S., \& Ingber, T. (1976). Achievement-treatment interactions in programmed instruction. Journal of Educational Psychology, 68, 43-47.

White, O.R., \& Haring, N.G. (1980). Exceptional Teaching. Columbus, OH: Bell \& Howell Company.

Williams, J. P. (1969). Effectiveness of constructed-response and multiple-choice programing modes as a function of test mode. In R. C. Anderson, G. W. Faust, M. C. Roderick, D. J. Cunningham, and T. Andre (Eds.), Current Research on Instruction (pp. 156-162). Englewood Cliffs, NJ: Prentice-Hall, Inc. Winer, B. J., Brown, D. R., \& Michels, K. M. (1991). Statistical principles in experimental design. McGraw-Hill, Inc: New York, pp. 479-481.

Wirt, J., \& Livingston, A. (2002). The condition of education 2002 in brief. (Report No. NCES2002-011). Washington, DC: National Center for Education Statistics. (ERIC Document Reproduction Service No. ED471875). 
Table 1. Training and testing sequence

Step 1 Pretesting

Basic Pretest

Exponent Pretest

Application Pretest

Problem Solving Pretest

Step 2 Training on Rule 1

Step 3 Testing

Disruption for Rule 1

Application

Problem Solving

Step 4 Training and Testing on Rules 2-5 (repeat steps 2 and 3 for each rule)

Step 5 Retention Test

Note: The retention posttest occurred two weeks after the testing sequence was completed for the fifth rule. 
Behavioral momentum 36

Table 2. Accuracy and rate data for all subjects on distraction tests (Dist) for each rule (Rx).

\begin{tabular}{|c|c|c|c|c|c|c|c|c|c|c|c|}
\hline & & Dist R1 & Dist R1 & Dist R2 & Dist R2 & Dist R3 & Dist R3 & Dist R4 & Dist R4 & Dist R5 & Dist R5 \\
\hline \multirow[t]{5}{*}{ HR } & TS & 96 & 5.18 & 72 & 4.68 & 96 & 4.43 & 96 & 7.87 & 92 & 3.42 \\
\hline & EL & 80 & 1.40 & 80 & 1.82 & 100 & 2.77 & 0 & 0.00 & 56 & 1.24 \\
\hline & LZ & 92 & 5.70 & 84 & 4.65 & 88 & 6.41 & 96 & 7.54 & 96 & 4.60 \\
\hline & AM & 80 & 5.26 & 80 & 5.48 & 84 & 4.63 & 84 & 4.96 & 96 & 2.99 \\
\hline & $A G$ & 100 & 3.05 & 92 & 2.95 & 96 & 3.29 & 100 & 3.77 & 92 & 2.54 \\
\hline \multirow[t]{4}{*}{ LR } & MM & 100 & 2.93 & 100 & 4.20 & 92 & 3.25 & 96 & 4.63 & 100 & 3.30 \\
\hline & MP & 100 & 7.39 & 100 & 5.38 & 92 & 4.68 & 100 & 7.54 & 100 & 4.67 \\
\hline & SM & 96 & 7.62 & 84 & 5.43 & 100 & 4.93 & 96 & 7.13 & 92 & 4.02 \\
\hline & $\mathrm{JC}$ & 100 & 4.57 & 96 & 7.87 & 96 & 6.61 & 100 & 9.62 & 96 & 7.16 \\
\hline
\end{tabular}


Table 3. Accuracy and rate data for all subjects on application tests (App) after each rule (Rx).

\begin{tabular}{|c|c|c|c|c|c|c|c|c|c|c|c|c|c|}
\hline & & App R1 & App R1 & App R2 & App R2 & App R3 & App R3 & App R4 & App R4 & App R5 & App R5 & Ret & Ret App \\
\hline Group & Subject & $\%$ & Rate & $\%$ & Rate & $\%$ & Rate & $\%$ & Rate & $\%$ & Rate & App \% & Rate \\
\hline \multirow[t]{6}{*}{ HR } & TS & 56 & 1.48 & 36 & 0.97 & 68 & 2.98 & 92 & 4.27 & 92 & 4.42 & 84 & 3.36 \\
\hline & EL & 32 & 0.57 & 48 & 0.52 & 84 & 1.38 & 52 & 0.91 & 56 & 1.14 & 60 & 1.01 \\
\hline & $\mathrm{LZ}$ & 48 & $2.04^{*}$ & 52 & 2.39 & 76 & 3.70 & 96 & 5.37 & 96 & 4.78 & 96 & 4.38 \\
\hline & DT & 60 & 1.40 & 52 & 1.88 & 84 & 5.25 & 80 & 4.94 & 44 & 2.39 & 84 & 4.03 \\
\hline & AM & 20 & 0.40 & 40 & 1.36 & 60 & 1.89 & 76 & 2.59 & 92 & 3.09 & 68 & 2.18 \\
\hline & $A G$ & 72 & 1.22 & 80 & 1.46 & 80 & 2.28 & 100 & 3.28 & 100 & 3.83 & 92 & 3.18 \\
\hline \multirow[t]{6}{*}{ LR } & MM & 64 & 1.56 & 64 & 1.85 & 88 & 2.57 & 100 & 3.72 & 96 & 3.48 & 96 & 2.95 \\
\hline & MP & 40 & 1.17 & 60 & 2.04 & 80 & 3.36 & 100 & 4.35 & 100 & 4.52 & 96 & 4.36 \\
\hline & JMU & 24 & 1.40 & 44 & 2.02 & 76 & 3.88 & 84 & 2.81 & 76 & 2.44 & 84 & 3.64 \\
\hline & NB & 28 & 1.13 & 48 & 1.98 & 72 & 2.73 & 92 & 1.60 & 84 & 2.55 & 80 & 1.99 \\
\hline & SM & 48 & 1.25 & 60 & 1.63 & 56 & 1.88 & 52 & 2.29 & 80 & 3.17 & 84 & 3.12 \\
\hline & $\mathrm{JC}$ & 40 & 1.50 & 52 & 3.41 & 76 & 3.28 & 84 & 4.85 & 64 & 3.71 & 76 & 3.67 \\
\hline
\end{tabular}

Note: The asterisk $\left(^{*}\right)$ indicates that the rate was calculated using estimated time measures. Time data from subjects EL and DT were used in the estimation. 
Table 4. Accuracy and rate data for all subjects on problem solving tests (PS) after each rule(Rx).

\begin{tabular}{|c|c|c|c|c|c|c|c|c|c|c|c|c|c|}
\hline & & PS R1 & PS R1 & PS R2 & PS R2 & PS R3 & PS R3 & PS R4 & PS R4 & PS R5 & PS R5 & Ret PS & Ret PS \\
\hline Group & Subject & $\%$ & Rate & $\%$ & Rate & $\%$ & Rate & $\%$ & Rate & $\%$ & Rate & $\%$ & Rate \\
\hline \multirow[t]{6}{*}{ HR } & TS & 16 & 0.17 & 8 & 0.12 & 32 & 0.38 & 52 & 0.56 & 52 & 0.61 & 48 & 0.61 \\
\hline & EL & 0 & 0.00 & 0 & 0.00 & 4 & 0.02 & 20 & 0.15 & 28 & 0.16 & 16 & 0.10 \\
\hline & LZ & 0 & $0.00^{*}$ & 0 & 0.00 & 8 & 0.55 & 72 & 1.19 & 64 & 0.85 & 80 & 1.15 \\
\hline & DT & 0 & 0.00 & 16 & 0.26 & 4 & 0.07 & 16 & 0.28 & 12 & 0.21 & 16 & 0.26 \\
\hline & AM & 0 & 0.00 & 0 & 0.00 & 0 & 0.00 & 28 & 0.35 & 12 & 0.77 & 12 & 0.15 \\
\hline & $A G$ & 52 & 0.49 & 20 & 0.22 & 16 & 0.15 & 96 & 0.98 & 96 & 1.29 & 100 & 1.15 \\
\hline \multirow[t]{6}{*}{ LR } & MM & 12 & 0.17 & 0 & 0.00 & 80 & 0.96 & 92 & 1.00 & 72 & 0.61 & 88 & 0.79 \\
\hline & MP & 0 & 0.00 & 0 & 0.00 & 20 & 0.31 & 80 & 1.04 & 96 & 1.18 & 96 & 1.50 \\
\hline & JMU & 0 & 0.00 & 0 & 0.00 & 4 & 0.33 & 8 & 0.58 & 24 & 0.79 & 20 & 0.95 \\
\hline & NB & 0 & 0.00 & 0 & 0.00 & 12 & 0.50 & 16 & 0.25 & 60 & 0.35 & 32 & 0.18 \\
\hline & SM & 0 & 0.00 & 16 & 0.18 & 4 & 0.05 & 4 & 0.04 & 32 & 0.33 & 8 & 0.12 \\
\hline & $\mathrm{JC}$ & 0 & 0.00 & 0 & 0.00 & 4 & 0.20 & 68 & 0.94 & 8 & 0.16 & 24 & 0.43 \\
\hline
\end{tabular}

Note: The asterisk $\left(^{*}\right)$ indicates that the rate was calculated using estimated time measures. Time data from subjects EL and DT were used in the estimation. 


\section{Figure Captions}

Figure 1. Means and standard errors for the number of timings required to reach the terminal criteria for each rule.

Figure 2. Means and standard errors of accuracy for each group across Distraction tests.

Figure 3. Means and standard errors of rates of correct responding for each group across Distraction tests.

Figure 4. Means and standard errors of accuracy for each group across Application tests.

Figure 5. Means and standard errors of rates of correct responding for each group across Application tests.

Figure 6. Means and standard errors of accuracy for each group across Problem Solving tests.

Figure 7. Means and standard errors of rates of correct responding for each group across Problem Solving tests.

Figure 8. Means and standard errors of accuracy for each group on Application and Problem Solving retention tests.

Figure 9. Means and standard errors of rates of correct responding for each group on Application and Problem Solving retention tests. 


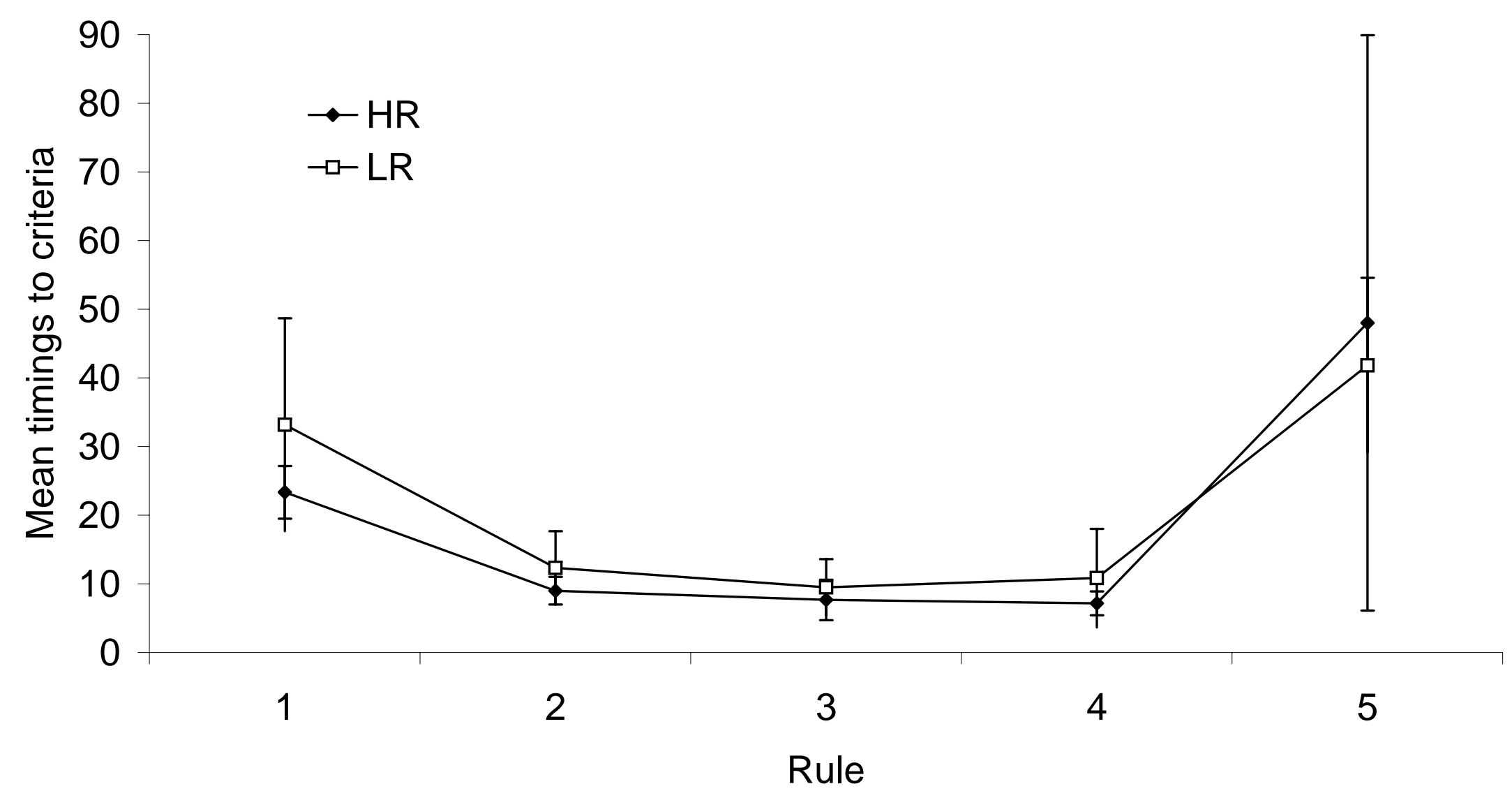




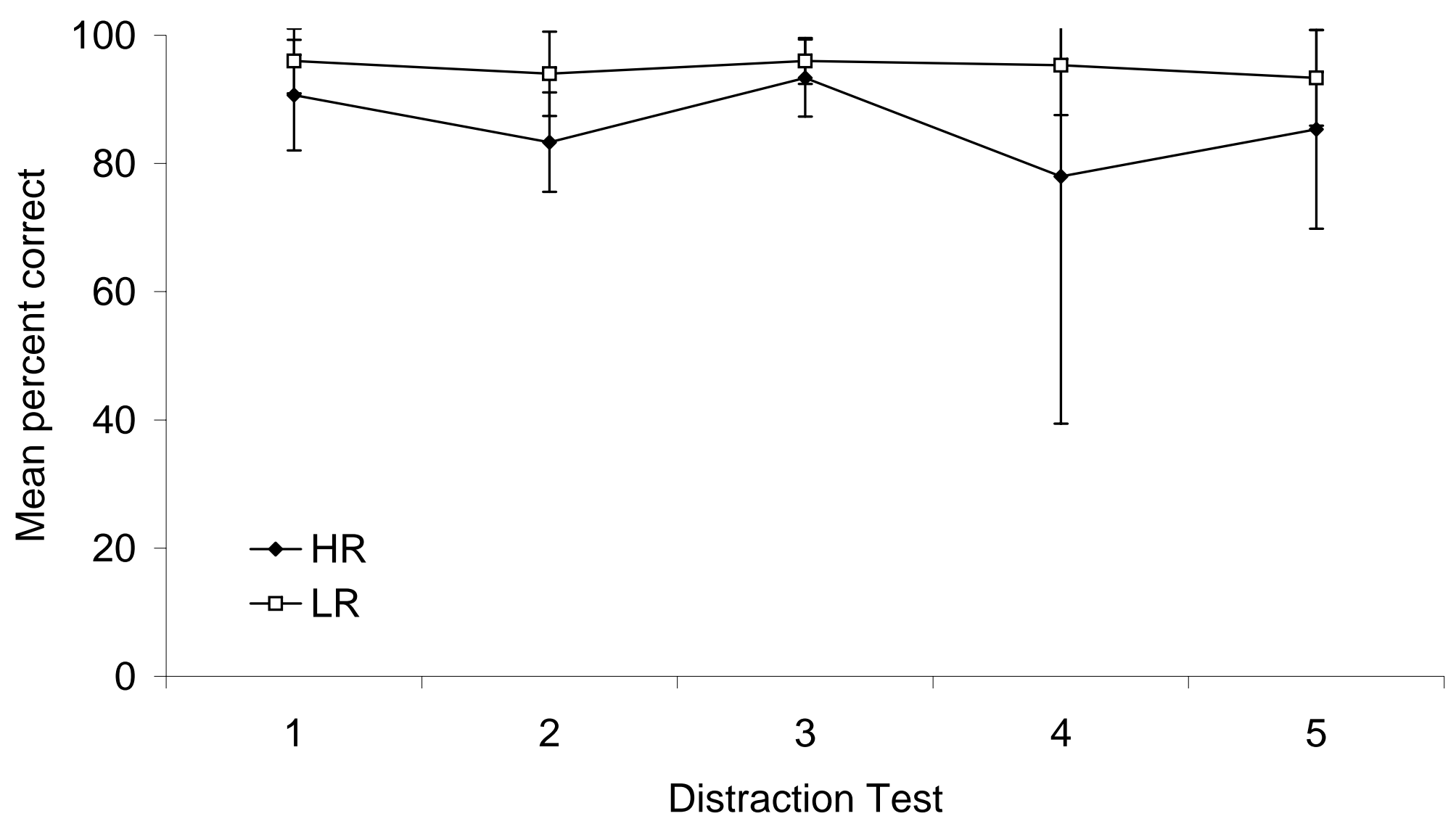




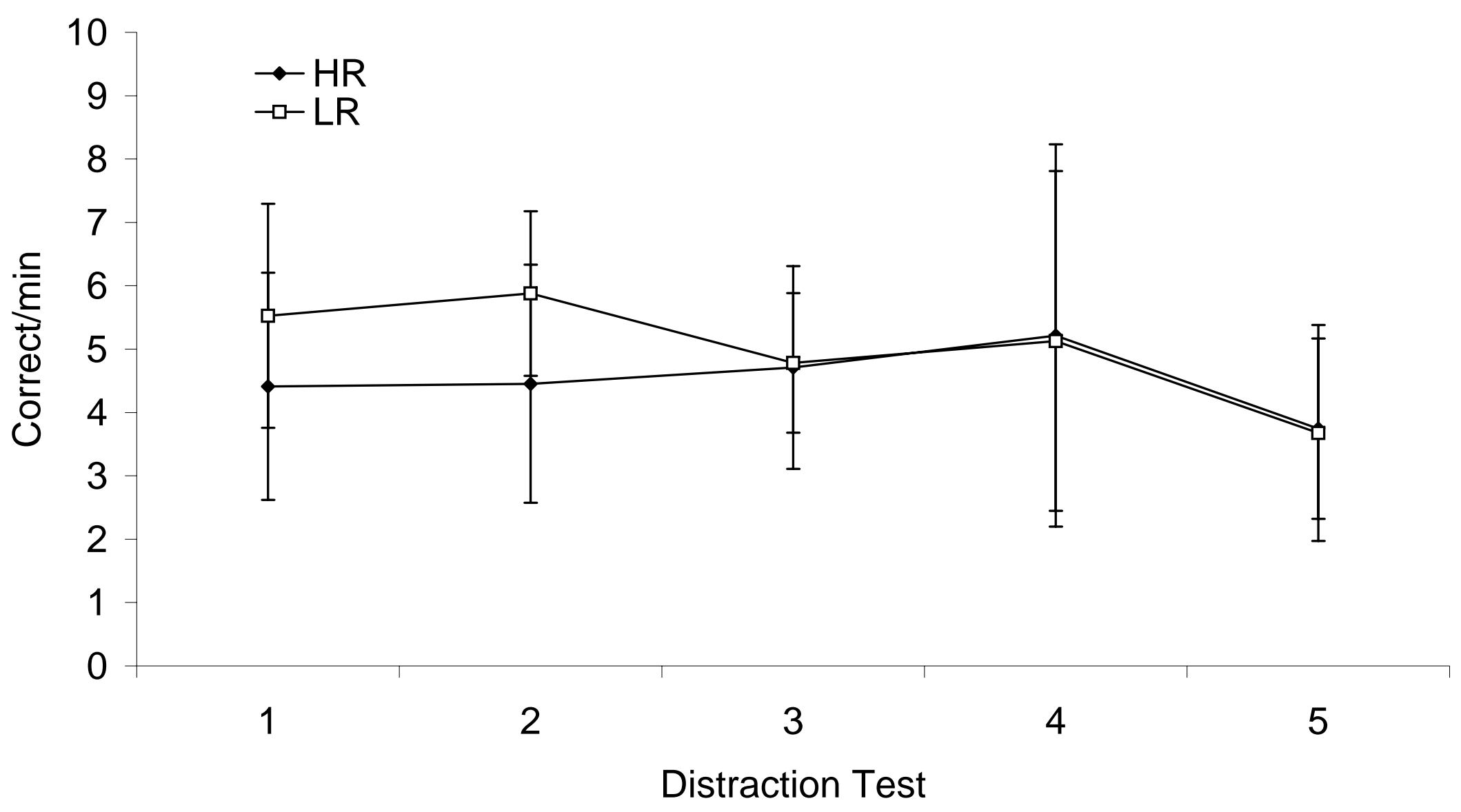




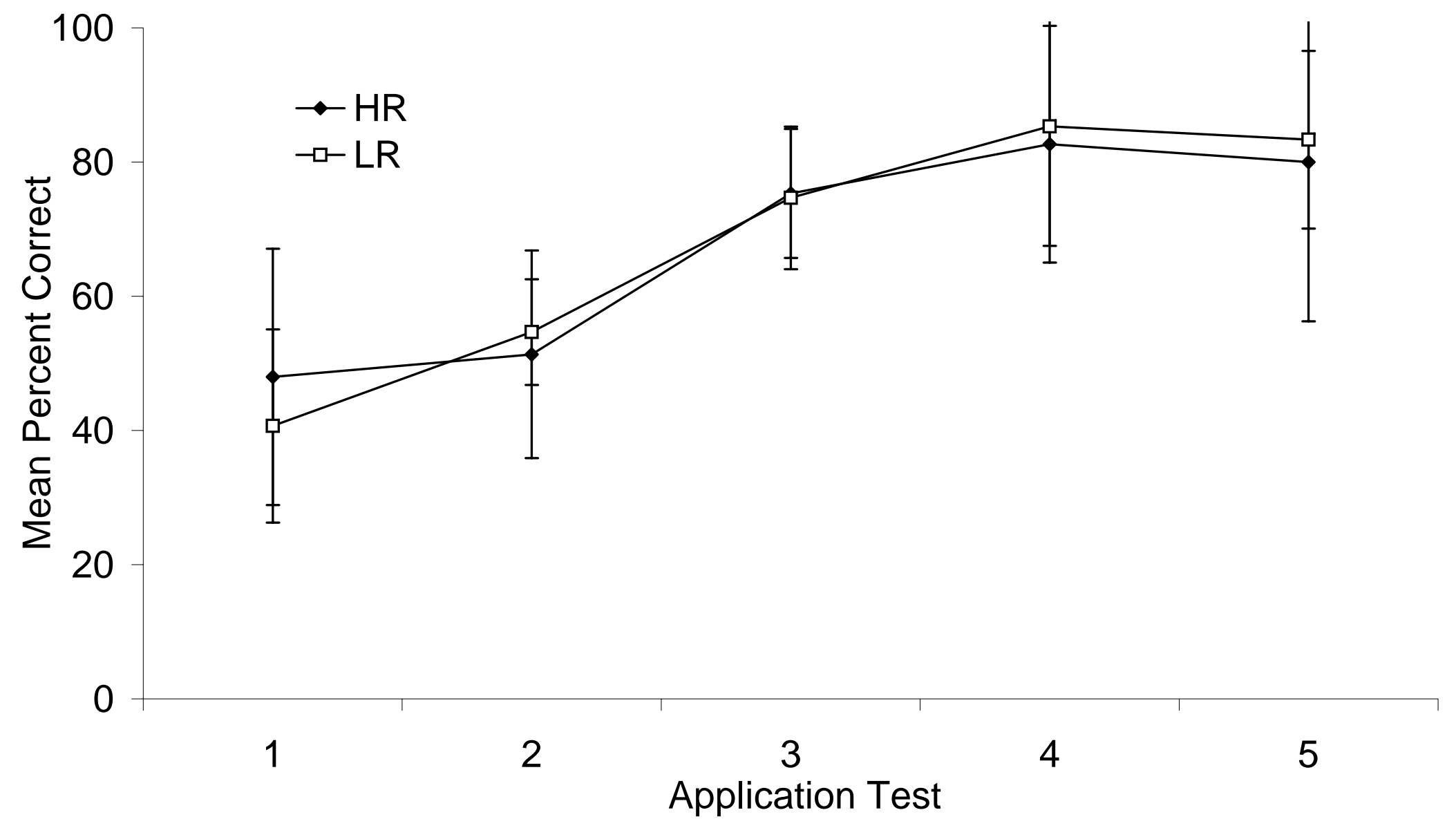




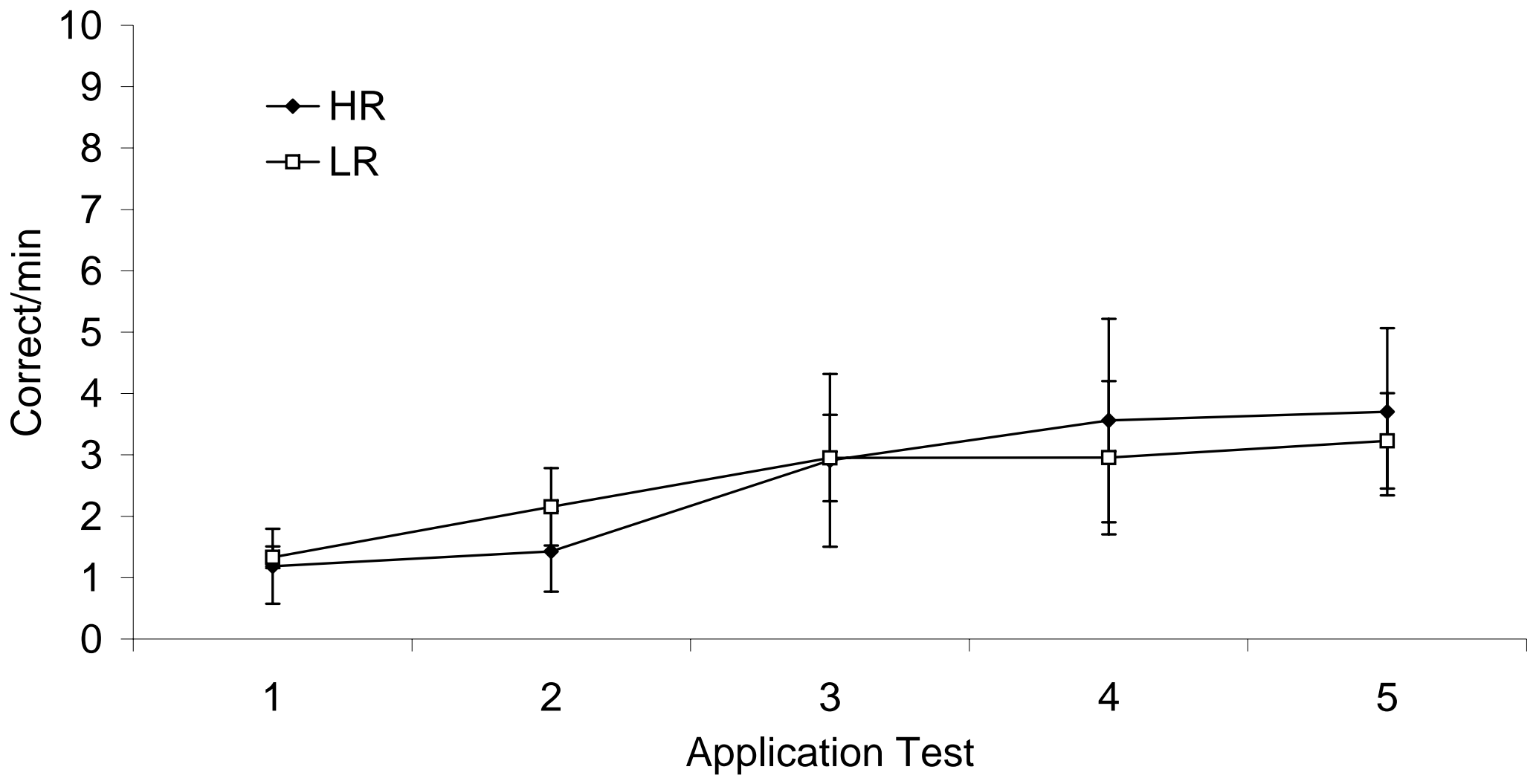




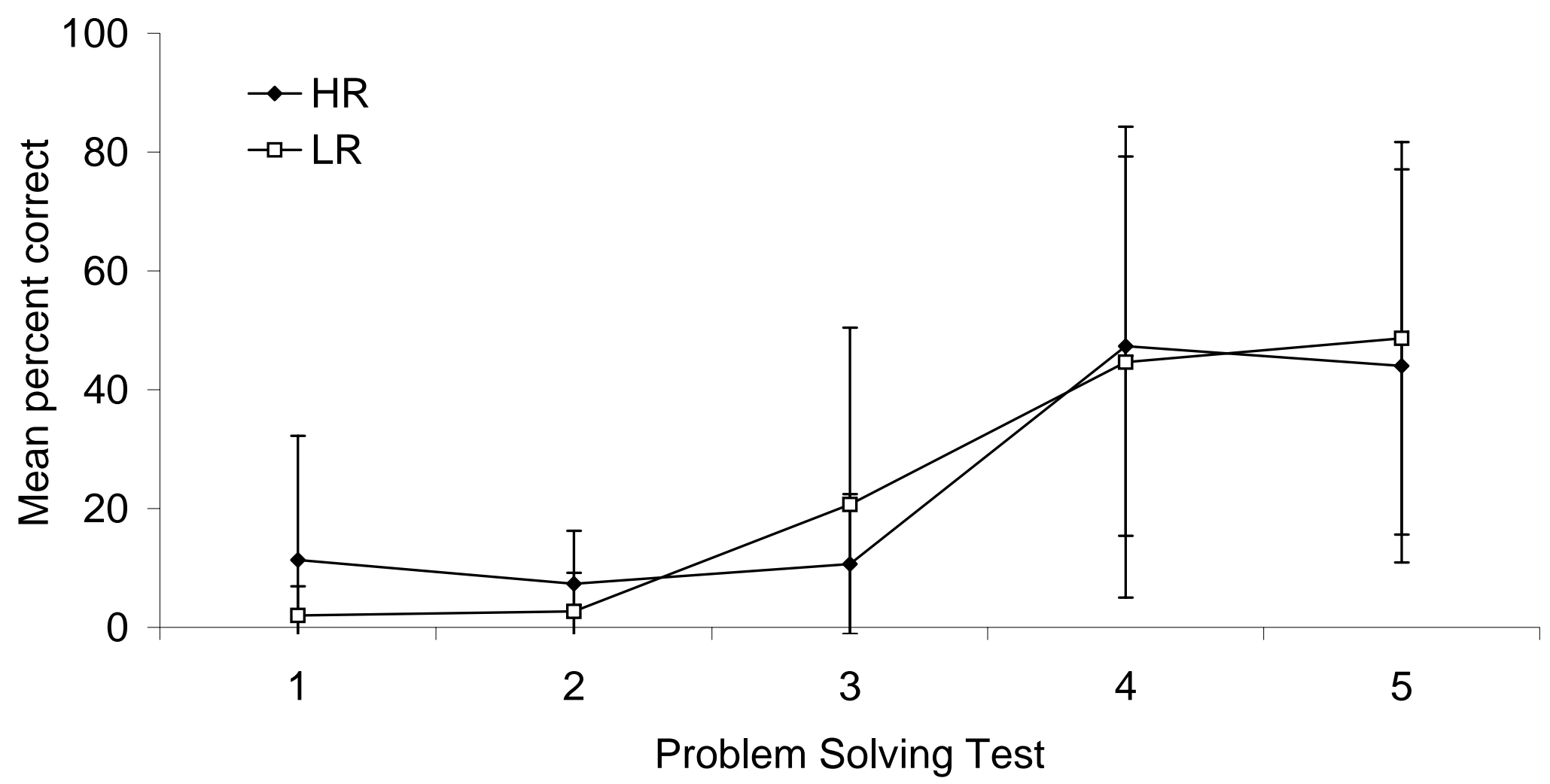




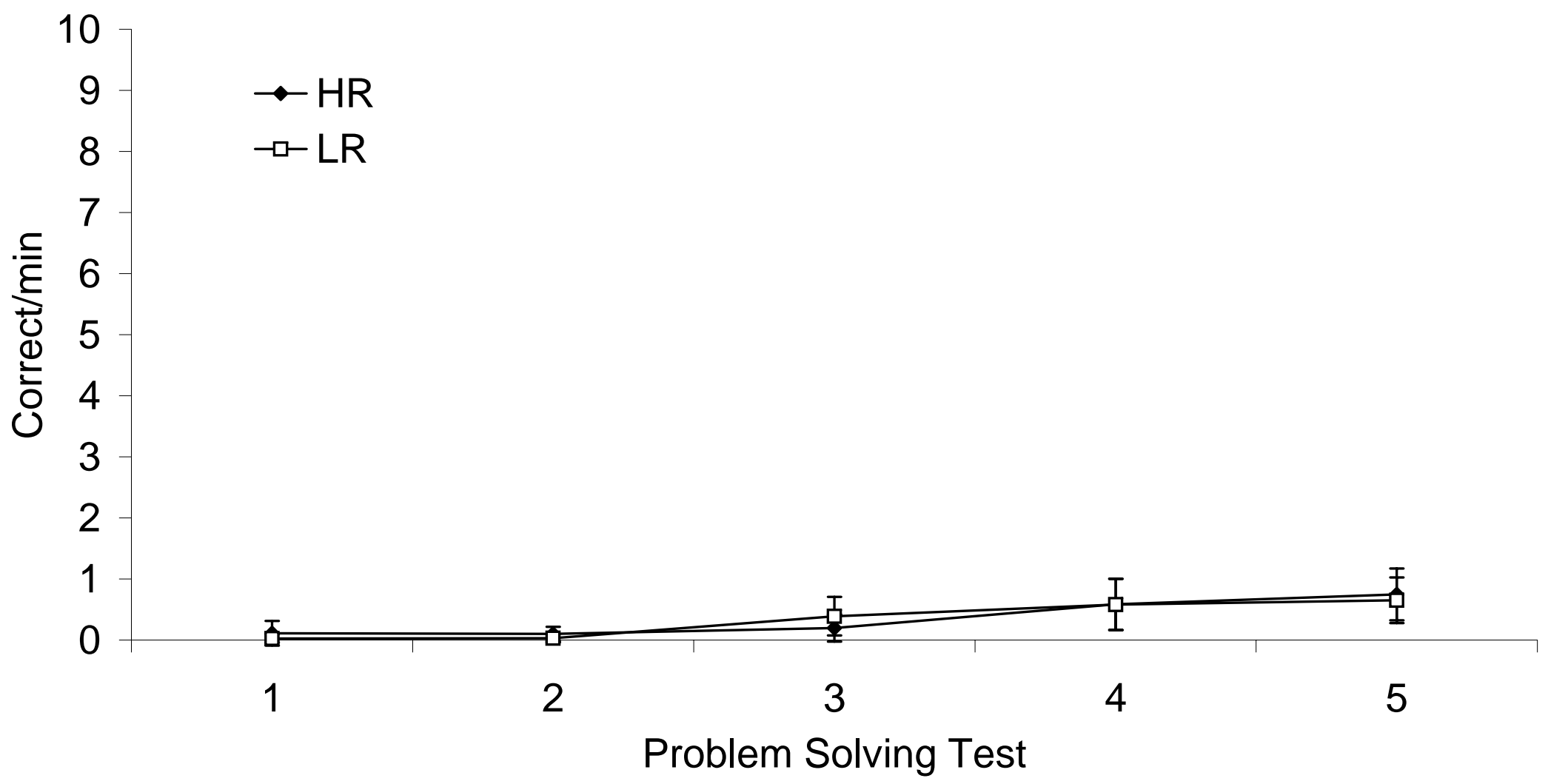




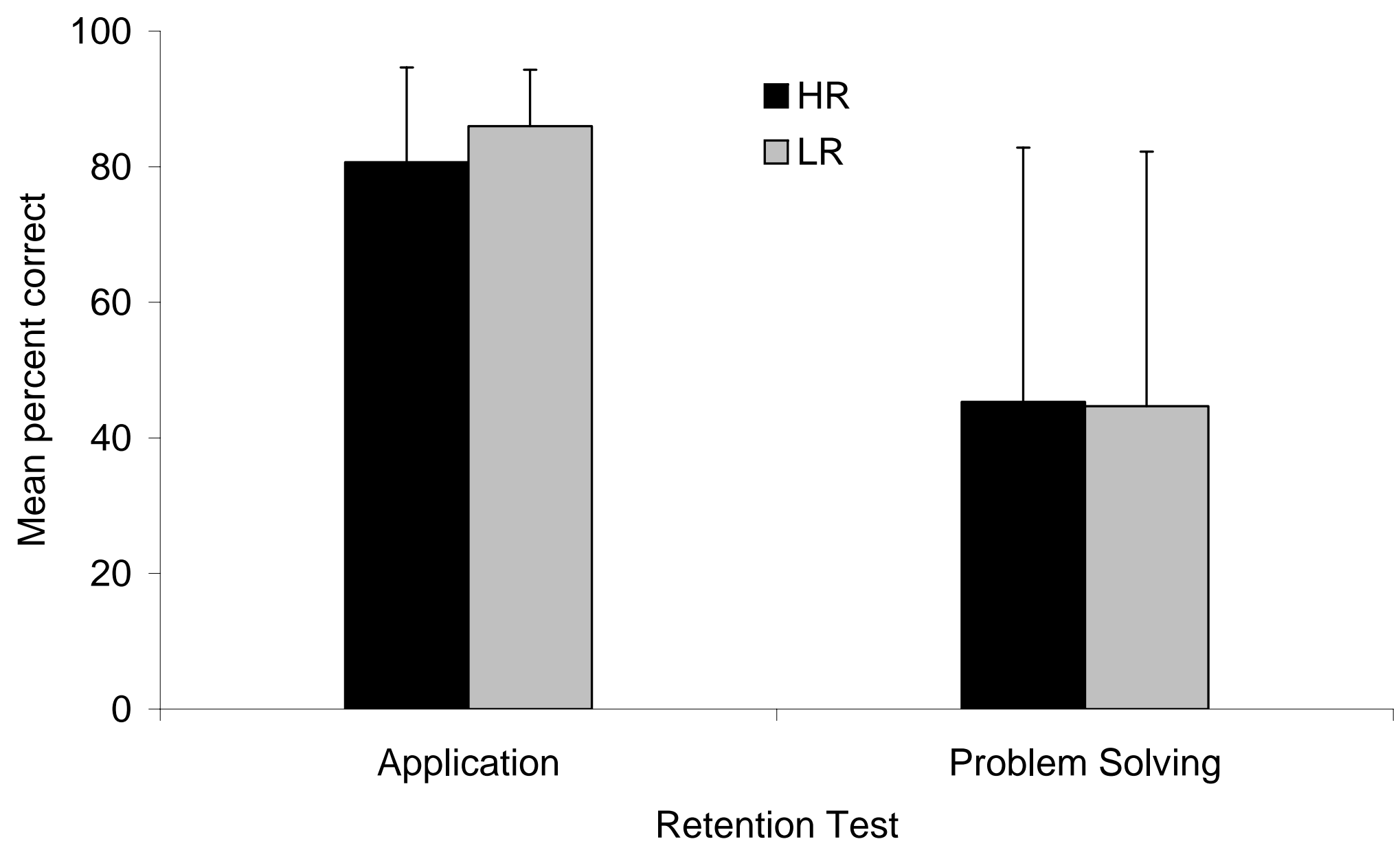




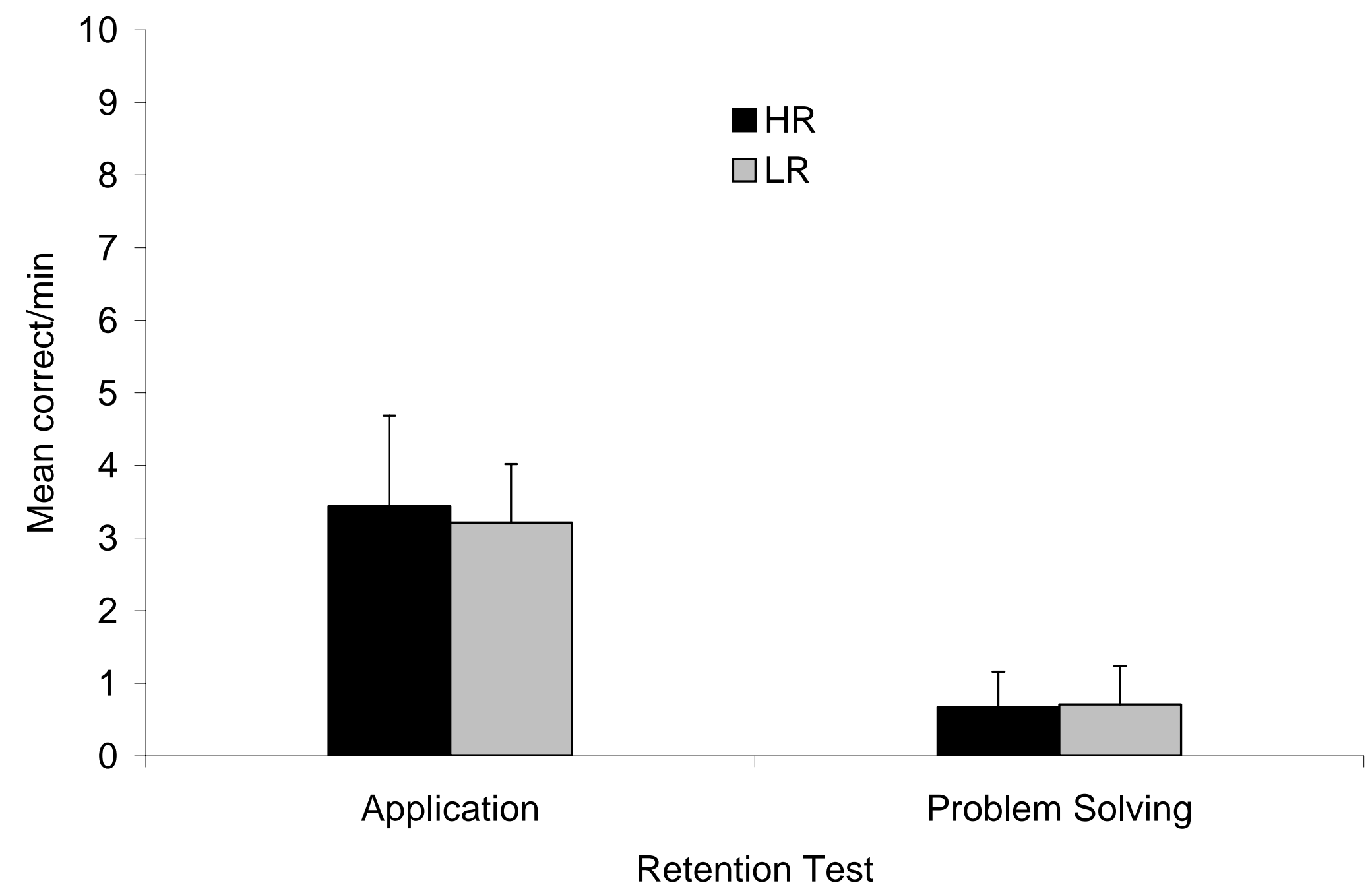




\section{Appendix A}

\section{Consent and Information Form}

Title: The role of behavioral momentum on fluency

\section{Introduction}

I, , have been invited to participate in this research study which has been explained to me by Vennessa L. Walker or one of her research assistants. This research is being conducted to fulfill the requirements for a master's thesis in Behavior Analysis in the Department of Psychology at West Virginia University.

\section{Purposes}

The purpose of this study is to assess various instructional techniques on learning mathematics skills.

\section{Description of Procedures}

This study will be conducted in the Verbal Behavior laboratory in the Department of Psychology at West Virginia University. I will be asked to complete a set of diagnostic tests to determine my eligibility for the study. If selected for the study, I will be randomly assigned to a group. I will be trained in a series of mathematical skills, using a computer to facilitate learning. After reaching a mastery criterion on a skill, I will undergo a series of tests before beginning my training on the next skill. Two weeks after completing the tests for the last skill, I will take a retention test. I understand that my participation will take approximately 1 hour per day, 5 days a week, for 2 weeks. If I fail to meet the selection requirements or training criteria, I will be terminated from the study. If I fail to attend a scheduled session without informing the experimenter beforehand, I will be terminated from the study. I understand that I will learn the math skills at my own pace; thus the length of the study may vary from approximately 2 weeks to 4 weeks.

\section{Risks and Discomforts}

There are no known or expected risks from participating in this study, except for mild frustration sometimes associated with performance on tests.

\section{Alternatives and Benefits}

I understand that I do not have to participate in this study. I understand that I can earn extra credit for my participation in this study and that other options are available for earning the same extra credit. I also understand that I may earn monetary reimbursement based on my performance, up to $\$ 50.00$. If I choose not to complete the study or if I am terminated from the study prior to its completion, I will receive any money I have earned upon my termination. I further understand that this study may benefit me by improving my mathematics skills. 


\section{Contact Persons}

For more information about this research, I can contact Vennessa Walker at (304) 6857477, or her supervisor, Dr. Philip N. Chase at (304) 293-2001 x 31626. For information regarding my rights as a research subject, I may contact the Executive Secretary of the Institutional Review Board at (304) 293-7073.

\section{Confidentiality}

I understand that any information about me obtained as a result of my participation in this research will be kept as confidential as legally possible. I understand that my research records and test results, just like hospital records, may be subpoenaed by court order or may be inspected by the study sponsor or federal regulatory authorities without my additional consent. In any publications that result from this research, neither my name nor any information from which I might be identified will be published without my consent.

\section{Voluntary Participation}

Participation in this study is voluntary. I understand that I am free to withdraw my consent to participate in this study at any time. Refusal to participate or withdrawal will involve no penalty or loss of benefits and will not affect any of my grades or class standing. I have been given the opportunity to ask questions about the research, and I have received answers concerning areas I did not understand. In the event new information becomes available that may affect my willingness to continue to participate in the study, this information will be given to me so I may make an informed decision about my participation.

Upon signing this form, I will receive a copy.

I willingly consent to participate in this study.

Signature of Participant

$\overline{\text { Date }} \overline{\text { Time }}$

Signature of Investigator or

Date

Time

Investigator's Representative 
Behavioral momentum 51

\section{Appendix B: Sample screen from Basic Math Test}

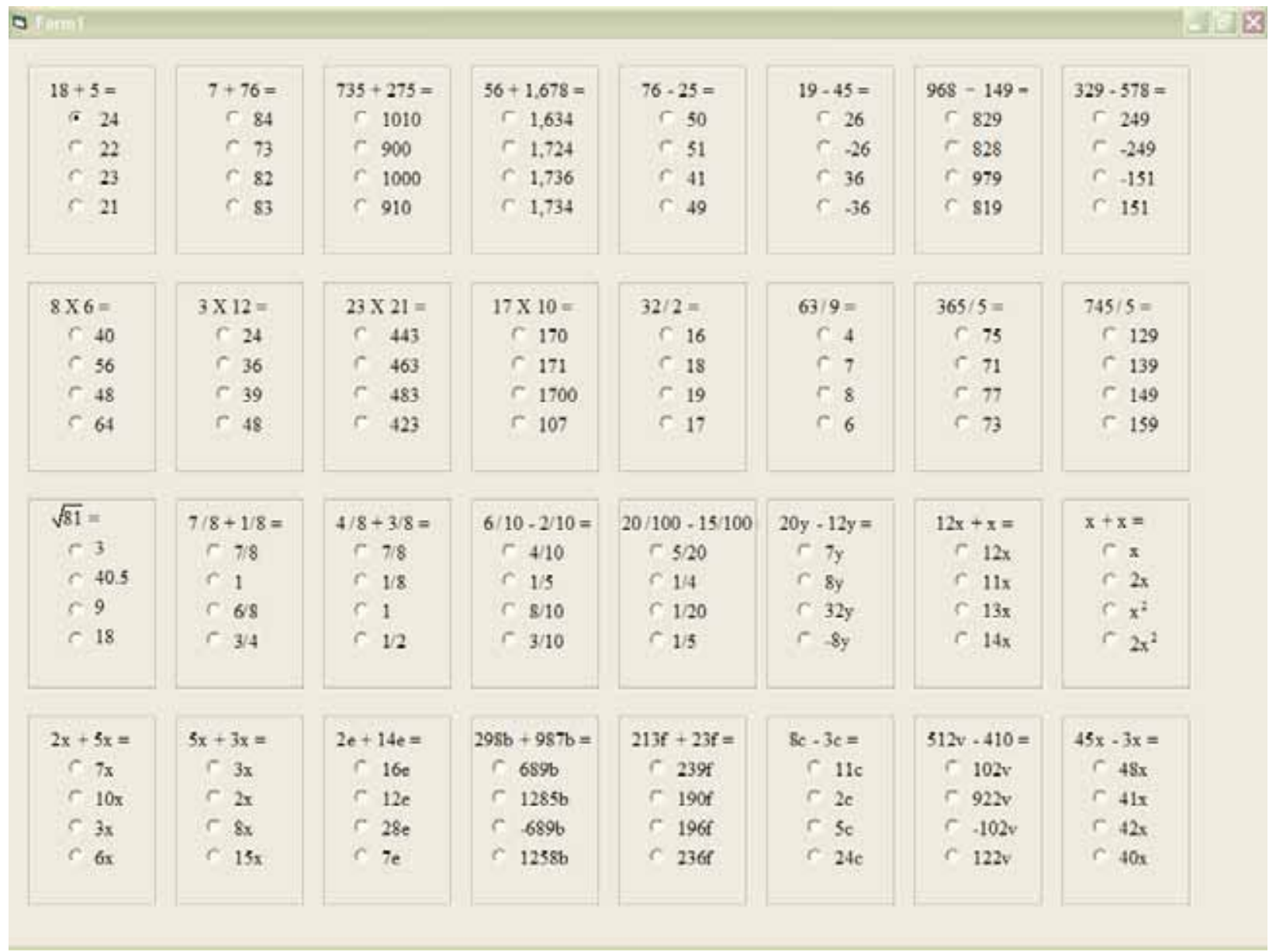


Behavioral momentum 52

\section{Appendix C: Basic Exponent Pretest}
$8 e^{4} \cdot 5 e^{7}=$
$9 v^{3} \cdot 8 v^{3}=$
$\left(8 r^{9}\right)\left(2 r^{6}\right)=$
$3 u^{8} \cdot 5 u^{9}=$
$2^{3} g^{5} \cdot 2^{8} g=$
$\left(4^{9} y^{3}\right)^{9}=$
$\frac{27 a^{7}}{9 a^{6}}=$
$\frac{21 t^{13}}{7 t^{7}}=$
$\frac{8^{14} w^{6}}{8^{5} w^{2}}=$
$\frac{10 m^{15}}{5 m^{6}}=$
$\frac{32 u^{12}}{8 u^{11}}=$
$\left(2 h^{1}\right)^{6}=$
$\left(2 y^{3}\right)^{3}=$
$(5 k)^{9}=$
$\left(2^{7} x^{3}\right)^{6}=$
$\frac{8+8}{12-8}=$
$(14-7)^{2}=$
$(12-9)^{2}+4=$
$\sqrt{(14-6)+8}=$
$\sqrt{\frac{18-9}{3}+6}=$
$\sqrt[8]{6^{64} q^{24}}=$
$\sqrt[4]{8^{28} k^{16}}=$
$\sqrt{1^{14} f^{6}}=$
$\sqrt[6]{3^{18} m^{36}}=$
$\sqrt[5]{2^{15} a^{20}}=$ 
Behavioral momentum 53

\section{Appendix D: Application Pretest}

1. $4^{3} s^{2} t^{6} \cdot 4^{9} s^{8} t^{7}=$

3. $\left(20^{6} x^{3} y^{7}\right)^{8}=$

5. $(15-9)^{4}=$

7. $\sqrt{\frac{18}{6}+\left(2^{2}-3\right)}=$

9. $\frac{4+8}{12-8}=$

11. $36 q^{18} p^{12} r^{13}=$ $9 q^{9} p^{7} r^{7}$
2. $\sqrt{5^{6} a^{18} b^{10}}=$

4. $\underline{7^{14} \mathrm{~g}^{13} \mathrm{~h}^{15}}=$ $7^{7} g^{6} h^{9}$

8. $\left(14 \mathrm{k}^{9} \mathrm{~m}^{4} \mathrm{n}^{8}\right)^{3}=$

10. $9 t^{5} u^{7} v^{8} \cdot 7 t^{4} u^{9} v^{5}=$

12. $\sqrt{(3 \cdot 3)+7}=$ 


\section{Appendix E: Problem Solving Pretest}

13. $\left(\frac{21 b^{11}}{3 b^{4}}\right)^{2}=$

14. $\left(8 x^{2} \cdot 7 x^{7}\right)^{9}=$

15. $\frac{\sqrt{8^{2} k^{6}}}{4 k}=$

16. $\sqrt[7]{5^{9} d^{5} \cdot 5^{5} d^{9}}=$

17. $\left(\frac{4 a^{3} \cdot 5 a^{5}}{2 a^{4}}\right)^{5}=$

18. $\left(\frac{\sqrt[3]{4^{6} y^{12}}}{4 y^{2}}\right)^{7}=$

19. $\sqrt[4]{\left(9 h^{2} \cdot 6 h^{1}\right)^{8}}=$

20. $\frac{\sqrt[5]{18^{5} f^{25}}}{2 f^{2} \cdot 3 f^{2}}=$

21. $\left(\frac{\sqrt[4]{36^{4} g^{12}}}{3 g^{1} \cdot 3 g}\right)^{9}=$

22. $\sqrt[3]{\frac{\left(3 h^{1} \cdot 3 h^{2}\right)^{6}}{h^{9}}}=$

23. $\frac{\sqrt{2^{4} t^{10}} \cdot\left(2 t^{4}\right)^{2}}{2 t^{5}}=$

24. $\frac{\left(3^{4} m^{6}\right)^{3}}{m^{9}} \cdot \sqrt[5]{1^{5} m^{45}}=$ 


\section{Appendix F: General Instructions to the Participants}

Instructions for the first training session:

Today you will be training on Rule 1 . When you click the continue button, you will see a screen with the rule and some examples. After you read the explanation of the rule and study the examples, you will begin training. Take a minute to read the instructions about what your goals are and how to earn points. Let me know if you have any questions. (Let them read). Okay, be sure to put your headphones on, and pay attention to the pop-up windows, and when it says "knock on the door", that just means the one in the wall, and we will review your answers.

Instructions for Payment and Extra Credit Procedures (prior to first training session):

You will be paid for both your performance during practice sessions as well as your performance on the tests. Each day you will be told how much money you earned during the session. You will be paid your earnings halfway through the study and then again at the end of the study, after you have taken the retention test. If you complete the study and have attended every scheduled session, you will receive a $\$ 1.00$ bonus for every session attended, payable at the end of the study. You will also receive an extra credit slip at the end of the study to turn in to your teacher.

Other Important Instructions (prior to first training session):

It is very important that you do not discuss anything about the skills you are learning in the study with anyone else. Moreover, please do not refer to mathematics textbooks or other sources of math instruction because that would interfere with the results of the study. Remember, the study is based on you receiving the instruction during your daily participation in the study! Thanks for your cooperation!

Instructions for subsequent training sessions:

Today you will be training on Rule __. Again, the goal is 13 per minute with $90 \%$ accuracy, and if you reach that, you will earn 5 points. You must reach that rate on 5 different timings during this session to complete training. You may also earn points by improving on your best previous performance by $1.25 x$ while still maintaining $90 \%$ accuracy. Wear the headphones for white noise, and pay attention to the pop-ups. When it says "knock on the door", that just means the one in the wall, and we will review your answers. 
Behavioral momentum 56

\section{Appendix G: Sample Rule Screen}

Rule 1

To multiply variables with exponents, $\mathrm{ADD}$ the exponents.

$$
\begin{array}{ll}
\text { Examples: } & \mathrm{a}^{2} \cdot \mathrm{a}^{3}=(\mathrm{a} \cdot \mathrm{a}) \cdot(\mathrm{a} \cdot \mathrm{a} \cdot \mathrm{a})=\mathrm{a}^{5} \quad \text { or } \mathrm{a}^{2+3}=\mathrm{a}^{5} \\
& \mathrm{x}^{5} \cdot \mathrm{x}^{9}=\mathrm{x}^{14} \\
& \left(\mathrm{~g}^{3}\right)(\mathrm{g})=\left(\mathrm{g}^{3}\right)\left(\mathrm{g}^{1}\right)=\mathrm{g}^{4} \quad\left(\text { Remember: } \mathrm{g}=\mathrm{g}^{1}\right) \\
& \mathrm{a}^{1} \cdot \mathrm{a}^{3}=\mathrm{a} \cdot(\mathrm{a} \cdot \mathrm{a} \cdot \mathrm{a})=\mathrm{a}^{4} \\
& \mathrm{a}^{0} \cdot \mathrm{a}^{3}=1 \cdot(\mathrm{a} \cdot \mathrm{a} \cdot \mathrm{a})=\mathrm{a}^{3} \quad\left(\text { Remember: } \mathrm{a}^{0}=1\right)
\end{array}
$$

If the variables have coefficients (numbers in front), MULTIPLY the coefficients as you would in a simple multiplication equation.

Examples: $3 \mathrm{x}^{5} \cdot 7 \mathrm{x}^{0}=3 \cdot 7=21 ; \mathrm{x}^{5} \cdot \mathrm{x}^{0}=(\mathrm{x} \cdot \mathrm{x} \cdot \mathrm{x}) \cdot 1=\mathrm{x}^{5}=21 \mathrm{x}^{5}$

$\left(t^{3}\right)\left(4 t^{5}\right)=\left(1 t^{3}\right)\left(4 t^{5}\right)=4 t^{8} \quad\left(\right.$ Remember: $\left.t^{3}=1 t^{3}\right)$

If the coefficients are the same number, you can leave the number the same and $\mathrm{ADD}$ the exponents just like you do for the variables.

Examples: $\left(2^{4} \mathrm{~g}^{3}\right)\left(2^{5} \mathrm{~g}\right)=\left(2^{4} \mathrm{~g}^{3}\right)\left(2^{5} \mathrm{~g}^{1}\right)=2^{9} \mathrm{~g}^{4}$

$5^{3} \mathrm{y}^{3} \cdot 5 \mathrm{y}^{4}=5^{3} \mathrm{y}^{3} \cdot 5^{1} \mathrm{y}^{4}=5^{4} \mathrm{y}^{7} \quad$ (Remember: $5=5^{1}$ )

$4 x^{2} \cdot 4 x^{5}=4^{1} x^{2} \cdot 4^{1} x^{5}=4^{2} x^{7}$ or $16 x^{7}$

(Notice here that you can use the rule, and write $4^{2}$, or you can immediately multiply 4 times 4 to get 16 . Either one is correct.) 
Behavioral momentum 57

\section{Appendix H: Sample Training Screen}

\begin{tabular}{|c|c|c|c|c|c|c|c|c|}
\hline $\begin{array}{c}\text { Your Points: } \\
0\end{array}$ & $\begin{array}{l}2 d^{5} \cdot 5 d^{4}= \\
<7 d^{9} \\
\sim 10 d^{9} \\
<10 d^{20} \\
<7 d^{20}\end{array}$ & $\begin{array}{l}8 h^{5} \cdot 5 h^{9}= \\
\left\ulcorner 40 h^{45}\right. \\
\sim 40 h^{14} \\
\sim 13 h^{14} \\
>13 h^{45}\end{array}$ & $\begin{array}{l}(9 r)\left(6 r^{3}\right)= \\
\left\ulcorner 54 r^{2}\right. \\
r 15 r^{4} \\
\left\ulcorner 54 r^{4}\right. \\
\left\ulcorner 15 r^{2}\right.\end{array}$ & $\begin{array}{c}3^{7} w^{4} \cdot 3^{8} w^{4}= \\
\sim 3^{56} w^{16} \\
\sim 3^{15} w^{16} \\
\sim 9^{15} w^{8} \\
\sim 3^{15} w^{8}\end{array}$ & $\begin{array}{l}6 \mathrm{~g}^{4} \cdot \mathrm{g}= \\
\sim 6 \mathrm{~g}^{5} \\
\sim 6^{2} \mathrm{~g}^{3} \\
\sim 6 \mathrm{~g}^{4} \\
\sim 6 \mathrm{~g}^{3}\end{array}$ & $\begin{array}{c}\left(2^{5} s^{7}\right)\left(2^{9} s^{9}\right)= \\
r \quad 2^{45} s^{63} \\
r \quad 4^{45} s^{63} \\
r \quad 4^{14} s^{16} \\
r \quad 2^{14} s^{16}\end{array}$ & $\begin{array}{c}\left(8^{3} n^{1}\right)\left(8^{7} n^{8}\right)= \\
\sim 64^{10} n^{9} \\
\sim 8^{10} n^{9} \\
\sim 8^{21} n^{8} \\
\sim 8^{10} n^{8}\end{array}$ & $\begin{array}{r}5 c^{4} \cdot 6 c^{2}= \\
r 30 c^{8} \\
\sim 11 c^{6} \\
\sim 30 c^{6} \\
\sim 11 c^{8}\end{array}$ \\
\hline & $\begin{array}{r}7 \mathrm{~h}^{6} \cdot 8 \mathrm{~h}^{0}= \\
\left\ulcorner 56 \mathrm{~h}^{6}\right. \\
\curvearrowright 15 \mathrm{~h}^{0} \\
\curvearrowright 56 \mathrm{~h}^{0} \\
\curvearrowright 15 \mathrm{~h}^{6}\end{array}$ & $\begin{array}{c}4^{5} y^{3} \cdot 4^{6} y^{6}= \\
\left\ulcorner 4^{30} y^{18}\right. \\
\left\ulcorner 4^{11} y^{18}\right. \\
\left\ulcorner 16^{11} y^{9}\right. \\
\left\ulcorner 4^{11} y^{9}\right.\end{array}$ & $\begin{array}{c}(7 \mathrm{k})\left(4 \mathrm{k}^{3}\right)= \\
\sim 11 \mathrm{k}^{3} \\
\sim 28 \mathrm{k}^{4} \\
\sim 28 \mathrm{k}^{3} \\
\sim 11 \mathrm{k}^{4}\end{array}$ & $\begin{array}{l}9 x^{9} \cdot 8 x^{6}= \\
\sim 72 x^{15} \\
\sim 72 x^{54} \\
<17 x^{54} \\
>17 x^{15}\end{array}$ & $\begin{array}{l}6 \mathrm{~b}^{8} \cdot 6 \mathrm{~b}^{3}= \\
\sim 36 \mathrm{~b}^{11} \\
\sim 36 \mathrm{~b}^{24} \\
\sim 6 \mathrm{~b}^{11} \\
\sim 6 \mathrm{~b}^{24}\end{array}$ & $\begin{array}{c}\left(3 t^{9}\right)\left(2 t^{4}\right)= \\
\sim 5 t^{13} \\
\sim 6 t^{13} \\
\sim 6 t^{36} \\
\sim 5 t^{36}\end{array}$ & 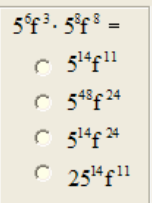 & $\begin{array}{l}5 \mathrm{j}^{8} \cdot 7 \mathrm{j}^{5}= \\
\sim 35 \mathrm{j}^{40} \\
\sim 35 \mathrm{j}^{13} \\
\left\ulcorner 12 \mathrm{j}^{40}\right. \\
\left\ulcorner 12 \mathrm{j}^{13}\right.\end{array}$ \\
\hline & $\begin{array}{c}9 \mathrm{e}^{9} \cdot 5 \mathrm{e}^{8}= \\
\sim 14 \mathrm{e}^{72} \\
\sim 45 \mathrm{e}^{72} \\
\sim 45 \mathrm{e}^{17} \\
\sim 14 \mathrm{e}^{17}\end{array}$ & $\begin{array}{c}8 \mathrm{v}^{7} \cdot 3 \mathrm{v}^{4}= \\
\left\ulcorner 24 \mathrm{v}^{28}\right. \\
\left\ulcorner 11 \mathrm{v}^{28}\right. \\
\left\ulcorner 11 \mathrm{v}^{11}\right. \\
\left\ulcorner 24 \mathrm{v}^{11}\right.\end{array}$ & $\begin{array}{c}\left(7^{3} \mathrm{r}\right)\left(7^{5} \mathrm{r}^{7}\right)= \\
\left\ulcorner 7^{15} \mathrm{r}^{7}\right. \\
\sim 7^{8} \mathrm{r}^{8} \\
\sim 49^{8} \mathrm{r}^{8} \\
\sim 7^{8} \mathrm{r}^{7}\end{array}$ & $\begin{array}{c}4 u^{4} \cdot 5 u^{8}= \\
\sim 9 u^{12} \\
\sim 9 u^{32} \\
\sim 20 u^{32} \\
\sim 20 u^{12}\end{array}$ & $\begin{array}{c}2^{0} \mathrm{~g}^{2} \cdot 2^{9} \mathrm{~g}= \\
r 2^{0} \mathrm{~g}^{2} \\
r 4^{9} \mathrm{~g}^{3} \\
r 2^{9} \mathrm{~g}^{3} \\
\left\ulcorner 2^{9} \mathrm{~g}^{2}\right.\end{array}$ & $\begin{array}{c}\left(1 y^{9}\right)\left(y^{9}\right)= \\
\sim 1 y^{18} \\
\sim 2 y^{81} \\
\sim 1 y^{81} \\
\sim 2 y^{18}\end{array}$ & $\begin{array}{c}\left(6 n^{4}\right)\left(8 n^{8}\right)= \\
\sim 14 n^{12} \\
\sim 48 n^{32} \\
\sim 48 n^{12} \\
\sim 14 n^{32}\end{array}$ & $\begin{array}{l}8 \mathrm{~d}^{9} \cdot 4 \mathrm{~d}^{3}= \\
\sim 12 \mathrm{~d}^{12} \\
\sim 32 \mathrm{~d}^{27} \\
\sim 12 \mathrm{~d}^{27} \\
r 32 \mathrm{~d}^{12}\end{array}$ \\
\hline & $\begin{array}{l}8^{7} \mathrm{t} \cdot 8 \mathrm{t}^{4}= \\
\sim 64^{8} \mathrm{t}^{5} \\
\sim 8^{8} \mathrm{t}^{5} \\
\sim 8^{7} \mathrm{t}^{4} \\
\sim 8^{7} \mathrm{t}^{5}\end{array}$ & $\begin{array}{r}9 w^{9} \cdot 7 w^{3}= \\
\sim 63 w^{27} \\
\sim 16 w^{12} \\
\sim 63 w^{12} \\
\sim 16 w^{27}\end{array}$ & $\begin{array}{c}(2 \mathrm{r})\left(5 \mathrm{r}^{2}\right)= \\
\sim 10 \mathrm{r}^{3} \\
\sim 10 \mathrm{r}^{2} \\
\sim 7 \mathrm{r}^{3} \\
\sim 7 \mathrm{r}^{2}\end{array}$ & $\begin{array}{c}3^{2} x^{8} \cdot 3^{8} x^{5}= \\
r 3^{16} x^{40} \\
r 3^{10} x^{40} \\
r 3^{10} x^{13} \\
\text { r } 9^{10} x^{13}\end{array}$ & $\begin{array}{c}\left(3 n^{8}\right)\left(9 n^{9}\right)= \\
r 27 n^{72} \\
r 12 n^{72} \\
r 12 n^{17} \\
<27 n^{17}\end{array}$ & $\begin{array}{l}3 \mathrm{v}^{2} \cdot 7 \mathrm{v}^{9}= \\
\sim 21 \mathrm{v}^{18} \\
\sim 10 \mathrm{v}^{11} \\
\sim 21 \mathrm{v}^{11} \\
\sim 10 \mathrm{v}^{18}\end{array}$ & $\begin{array}{l}5^{8} \mathrm{j}^{5} \cdot 5^{9} \mathrm{j}^{7}= \\
\sim 5^{17} \mathrm{j}^{12} \\
\left\ulcorner 25^{17} \mathrm{j}^{12}\right. \\
\sim 5^{72} \mathrm{j}^{35} \\
\left\ulcorner 5^{17} \mathrm{j}^{35}\right.\end{array}$ & $\begin{array}{l}9 \mathrm{t}^{2} \cdot 8 \mathrm{t}^{6}= \\
\sim 72 \mathrm{t}^{12} \\
\sim 17 \mathrm{t}^{12} \\
\sim 17 \mathrm{t}^{8} \\
\sim 72 \mathrm{t}^{8}\end{array}$ \\
\hline
\end{tabular}


Behavioral momentum 58

\section{Appendix I: Sample Distraction Test}

Test 1- Rule 2

$\begin{array}{llrl}\frac{12 x^{16}}{6 x^{8}}= & \frac{80 x^{8}}{8 x^{7}}= & \frac{120 w^{10}}{40 w^{4}}= & \frac{16 x^{12}}{2 x^{11}}= \\ \frac{20 u^{11}}{4 u^{6}}= & \frac{63 b^{15}}{7 b^{8}}= & \frac{21 x^{11}}{7 x^{7}}= & \frac{32 x^{14}}{16 x^{6}}= \\ \frac{16^{12} r^{14}}{16^{3} r^{8}}= & \frac{64 x^{11}}{8 x^{10}}= & \frac{36 x^{10}}{9 x^{7}}= & \frac{18 x^{14}}{6 x^{5}}= \\ \frac{18 x^{14}}{9 x^{7}}= & \frac{24 k^{13}}{4 k^{9}}= & \frac{48 m^{10}}{8 m^{2}}= & \frac{17^{14} x^{8}}{17^{8} x^{4}}= \\ \frac{60 m^{10}}{6 m^{3}}= & \frac{19^{15} x^{8}}{19^{10} x^{4}}= & \frac{21 x^{13}}{7 x^{4}}= & \frac{45 k^{10}}{3 x^{4}}= \\ \frac{30 k^{10}}{15 k^{2}}= & \frac{12 x^{16}}{12 x^{9}}= & 5 k^{13} \\ & & \end{array}$

$\frac{12 x^{16}}{4 x^{9}}=$ 
Behavioral momentum 59

\section{Appendix J: Sample Application Test}

\section{Test 2- Rule 3}
$\left(6 d^{7} g^{5}\right)\left(7 d^{2} g^{7}\right)=$
$10 \mathrm{~h}^{6} \mathrm{i}^{2} \cdot 8 \mathrm{~h}^{6} \mathrm{i}^{9}=$
$2 w^{2} z^{7} \cdot 4 w^{9} z^{8}=$
$\left(3 b^{9} c^{5}\right)\left(8 b^{8} c^{9}\right)=$
$\left(9^{4} c^{7} d^{4}\right)(9$
$\frac{28 j^{17} k^{9}}{4 j^{8} k^{3}}=$
$\frac{30 j^{6} k^{10}}{5 j^{3} k^{2}}=$
$\frac{12 x^{16} y^{15}}{2 x^{9} y^{12}}=$
$\frac{32 x^{15} y^{13}}{8 x^{7} y^{8}}=$
$\left(5 r^{6} s^{8}\right)^{2}=$
$\left(75^{1} w^{5} z^{9}\right)^{3}=$
$\left(13 p^{3} q^{4}\right)^{6}=$
$\sqrt{8^{10} f^{4} g^{12}}=$
$\sqrt[9]{2^{63} h^{45} j^{27}}=$
$\sqrt[4]{5^{16} k^{12} m^{36}}=$
$\sqrt[2]{8^{12} c^{6} d^{18}=}$
$\sqrt[3]{5^{21} r^{12} s^{27}}=$
$(18-8)^{9}=$
$(90-30)^{4}=$
$\sqrt{(2 \cdot 5)+15}=$
$\sqrt{\frac{18}{3}+(3+0)}=$
$\frac{9+7}{10-8}=$ 
Behavioral momentum 60

\section{Appendix K: Sample Problem Solving Test}

Test 3- Rule 4

$$
\begin{aligned}
& \left(\frac{45 d^{13}}{5 d^{9}}\right)^{8}=\quad\left(5^{3} h^{4} \cdot 5^{3} h^{5}\right)^{8}=\quad \frac{2^{10} c^{12}}{\sqrt[5]{2^{35} c^{30}}}=\quad \sqrt[8]{14^{8} n^{2} \cdot 14^{8} n^{6}}= \\
& \left(\frac{36 t^{16}}{6 t^{8}}\right)^{8}=\quad\left(7^{2} h^{8} \cdot 8^{3} h^{0}\right)^{3}=\quad \frac{9^{18} t^{12}}{\sqrt[4]{9^{28} t^{40}}}=\quad \sqrt[4]{12^{4} f^{7} \cdot 12^{12} f^{4}}= \\
& \left(\frac{56 j^{15}}{4 j^{3} \cdot 2 j^{4}}\right)^{3}=\quad\left(\frac{\sqrt[9]{6^{63} r^{36}}}{6^{4} r}\right)^{4}=\quad \sqrt[6]{\left(5^{3} f^{4} \cdot 5^{5} f^{4}\right)^{3}}=\quad \frac{\sqrt{6^{18} y^{16}}}{6^{3} y^{1} \cdot 6^{5} y^{6}}= \\
& \left(\frac{45 g^{13}}{3 g^{5} \cdot 3 g^{4}}\right)^{7}=\quad\left(\frac{\sqrt[6]{8^{42} b^{18}}}{8^{4} b^{2}}\right)^{6}=\quad \sqrt[5]{\left(6^{8} i^{7} \cdot 6^{12} i^{3}\right)^{2}}=\quad \frac{\sqrt[3]{9^{27} p^{36}}}{9^{4} p^{6} \cdot 9^{3} p^{3}}= \\
& \left(\frac{9^{8} t^{6} \cdot 9 t^{7}}{\sqrt[3]{9^{18} t^{27}}}\right)^{6}=\quad \sqrt[4]{\frac{\left(8^{6} z^{4} \cdot 8 z^{4}\right)^{2}}{8^{6} z^{8}}}=\quad \frac{\sqrt[8]{20^{32} h^{56}} \cdot\left(20^{4} h^{3}\right)^{2}}{20^{5} h^{5}}=\sqrt[6]{17^{36} m^{48}} \cdot \frac{\left(17^{3} m^{2}\right)^{5}}{17^{7} m^{5}}= \\
& \left(\frac{5^{5} t^{3} \cdot 5^{0} t^{4}}{\sqrt[3]{5^{9} t^{15}}}\right)^{7}=\quad \sqrt[7]{\frac{\left(9^{2} a^{4} \cdot 9 a^{3}\right)^{6}}{9^{11} a^{14}}}=\frac{\sqrt[7]{8^{28} i^{56}} \cdot\left(8^{2} i^{3}\right)^{9}}{8^{9} i^{15}}=
\end{aligned}
$$

